\title{
Excitatory Effects of Parvalbumin-Expressing Interneurons Maintain Hippocampal Epileptiform Activity via Synchronous Afterdischarges
}

\author{
Tommas J. Ellender, ${ }^{1 \star}$ Joseph V. Raimondo, ${ }^{1,2 *}$ Agnese Irkle, ${ }^{1}$ Karri P. Lamsa, ${ }^{1,3}$ and Colin J. Akerman ${ }^{1}$ \\ ${ }^{1}$ Department of Pharmacology, University of Oxford, Oxford, OX1 3QT, United Kingdom, ${ }^{2}$ Medical Research Council Receptor Biology Unit, Institute of \\ Infectious Disease and Molecular Medicine, Faculty of Health Sciences, University of Cape Town, Cape Town, Western Cape, 7701, South Africa, and \\ ${ }^{3}$ Medical Research Council Anatomical Neuropharmacology Unit, Department of Pharmacology, University of Oxford, Oxford, OX1 3TH, United Kingdom
}

\begin{abstract}
Epileptic seizures are characterized by periods of hypersynchronous, hyperexcitability within brain networks. Most seizures involve two stages: an initial tonic phase, followed by a longer clonic phase that is characterized by rhythmic bouts of synchronized network activity called afterdischarges (ADs). Here we investigate the cellular and network mechanisms underlying hippocampal ADs in an effort to understand how they maintain seizure activity. Using in vitro hippocampal slice models from rats and mice, we performed electrophysiological recordings from CA3 pyramidal neurons to monitor network activity and changes in GABAergic signaling during epileptiform activity. First, we show that the highest synchrony occurs during clonic ADs, consistent with the idea that specific circuit dynamics underlie this phase of the epileptiform activity. We then show that ADs require intact GABAergic synaptic transmission, which becomes excitatory as a result of a transient collapse in the chloride $\left(\mathrm{Cl}^{-}\right)$reversal potential. The depolarizing effects of GABA are strongest at the soma of pyramidal neurons, which implicates somatic-targeting interneurons in AD activity. To test this, we used optogenetic techniques to selectively control the activity of somatic-targeting parvalbumin-expressing $\left(\mathrm{PV}^{+}\right)$interneurons. Channelrhodopsin-2-mediated activation of $\mathrm{PV}^{+}$interneurons during the clonic phase generated excitatory GABAergic responses in pyramidal neurons, which were sufficient to elicit and entrain synchronous AD activity across the network. Finally, archaerhodopsin-mediated selective silencing of PV ${ }^{+}$ interneurons reduced the occurrence of ADs during the clonic phase. Therefore, we propose that activity-dependent $\mathrm{Cl}^{-}$accumulation subverts the actions of $\mathrm{PV}^{+}$interneurons to perpetuate rather than terminate pathological network hyperexcitability during the clonic phase of seizures.
\end{abstract}

Key words: chloride; epilepsy; GABAA; hippocampus; optogenetics; parvalbumin

\section{Introduction}

Epilepsy is a debilitating condition characterized by recurrent seizures that reflect periods of enhanced excitability and synchronization within brain networks. Most seizures involve two stages: an initial tonic phase, followed by a longer period of rhythmic afterdischarges (ADs) known as the clonic phase (McCormick and Contreras, 2001). Previous studies have focused primarily on

\footnotetext{
Received April 30, 2014; revised Sept. 23, 2014; accepted Sept. 29, 2014

Author contributions: T.J.E., J.V.R., and C.J.A. designed research; T.J.E., J.V.R., and A.I. performed research; K.P.L. contributed unpublished reagents/analytic tools; T.J.E., J.V.R., and A.I. analyzed data; T.J.E., J.V.R., and C.J.A. wrote the paper.

We thank Peter Somogyi for support and use of equipment. This work was supported by Medical Research Council Grant G0601503, and the research leading to these results has received funding from the European Research Council under the European Community Seventh Framework Programme (FP7/2007-2013), European Research Council Grant Agreement 243273. J.V.R. was supported by a Rhodes Scholarship, a National Research Foundation Innovation Postdoctoral Fellowship, and a University of Cape Town University Research Council Postdoctoral Fellowship.

*T.J.E. and J.V.R. contributed equally to this work.

The authors declare no competing financial interests.

Correspondence should be addressed to Colin Akerman, Department of Pharmacology, Mansfield Road, OX1 3TH, Oxford, UK. E-mail: colin.akerman@pharm.ox.ac.uk.

DOI:10.1523/JNEUROSCI.1747-14.2014

Copyright $\odot 2014$ the authors $\quad 0270-6474 / 14 / 3415208-15 \$ 15.00 / 0$
}

the initiation of the tonic phase and how a network may generate, or succumb to, an ictal event (Trevelyan et al., 2006, 2007a,b; Ziburkus et al., 2006; Zhang et al., 2012; Cammarota et al., 2013). In comparison, less is known about the cellular and network mechanisms that maintain the continuing dynamics of the clonic phase. This phase manifests as ADs during which the network exhibits almost perfectly synchronous activity, typically in the form of depolarizing bursts (Trevelyan et al., 2007a; Isomura et al., 2008; Ilie et al., 2012). Experiments in humans and animal models support the idea that synchronous network activity increases during a seizure, becoming highest during the clonic phase (Schindler et al., 2007; Trevelyan et al., 2007a; Kramer et al., 2012; Schevon et al., 2012; Jiruska et al., 2013). These changes suggest that specific circuit dynamics underlie clonic ADs, but the mechanisms underlying the increased synchrony are not understood.

$\mathrm{GABA}_{\mathrm{A}} \mathrm{R}$ activation via different GABAergic interneuron subtypes plays a crucial role in synchronizing network activity (Somogyi and Klausberger, 2005). However, in the context of seizure activity, the effects of $\mathrm{GABA}_{\mathrm{A}} \mathrm{R}$ activation may be quite different. Intense $\mathrm{GABA}_{\mathrm{A}} \mathrm{R}$ activity can result in large chloride $\left(\mathrm{Cl}^{-}\right)$influxes (Isomura et al., 2003; Fujiwara-Tsukamoto et al., 2006, 
2007), which can result in a collapse in the transmembrane $\mathrm{Cl}^{-}$ gradient and depolarizing shift in the reversal potential of the $\mathrm{GABA}_{\mathrm{A}} \mathrm{R}\left(E_{\mathrm{GABAA}}\right.$; Thompson and Gahwiler, 1989; Staley et al., 1995; Kaila et al., 1997). This depolarizing shift has been suggested to contribute to synchronized activity patterns observed in epileptiform activity (Michelson and Wong, 1991; FujiwaraTsukamoto et al., 2010). Indeed, $\mathrm{GABA}_{\mathrm{A}} \mathrm{R}$ activation can be sufficient to induce ADs (Fujiwara-Tsukamoto et al., 2003), and the activity of subpopulations of interneurons, specifically fastspiking interneurons, correlates tightly with ADs (FujiwaraTsukamoto et al., 2006, 2010). However, it is unknown whether somatic and dendritic compartments exhibit similar depolarizing GABA effects during ADs and how this might influence the contribution of interneurons that target specific subcellular domains.

Using in vitro models of hippocampal epileptiform activity, we demonstrate that GABAergic transmission becomes depolarizing and excitatory during the clonic phase. The transient depolarizing shift in GABAergic signaling is most pronounced at the soma of hippocampal pyramidal neurons, which means that somatic-targeting interneurons are well placed to synchronize excitatory effects across the network. Indeed, selective optogenetic activation of somatic-targeting parvalbumin-expressing $\left(\mathrm{PV}^{+}\right)$interneurons is sufficient to trigger and entrain ADs. In contrast, optogenetically silencing $\mathrm{PV}^{+}$interneurons during the clonic phase reduces the incidence of ADs. Our results suggest that, once a seizure is established, GABA released perisomatically by $\mathrm{PV}^{+}$interneurons can perpetuate the seizure through the direct generation of clonic ADs.

\section{Materials and Methods}

Animals. Experiments were performed on Wistar rats and PV-Cre mice, which were bred and housed in accordance with the United Kingdom Animals (Scientific Procedures) Act (1986) and the Society for Neuroscience policy on the use of animals in neuroscience research. PV-Cre mice express Cre recombinase in all $\mathrm{PV}^{+}$neurons and were obtained from The Jackson Laboratory (http://jaxmice.jax.org/strain/008069. html) and maintained as a homozygous breeding line.

Viral delivery. Adeno-associated virus serotype 2 (AAV2) carrying fusion genes for channelrhodopsin-2 (ChR2) or archaerhodopsin (Arch) were injected into the ventral hippocampus of PV-Cre mice between postnatal days 14 and 21. Typical coordinates from bregma were 2.55 $\mathrm{mm}$ lateral, $2.65 \mathrm{~mm}$ posterior, and $3.25 \mathrm{~mm}$ depth from the surface of the brain. During the injection, the needle was retracted to a depth of $2.25 \mathrm{~mm}$ from the surface of the brain to maximize the spread of virus throughout the hippocampus. Viral DNA included the double-floxed sequence for ChR2(H134R)-EYFP driven by the elongation factor 1 promoter or the double-floxed sequence for Arch-GFP driven by the CAG promoter. AAV2 particles were produced at the University of North Carolina Gene Therapy Center Vector Core and at the University of Pennsylvania Penn Vector Core. Typical titers were $\sim 10^{12}$ $\mathrm{IU} / \mathrm{ml}$, and injection volumes were 300-600 $\mathrm{nl}$. After allowing 4-8 weeks for ChR2 or Arch expression, acute hippocampal slices were prepared.

Slice preparation. Acute mouse hippocampal slices were prepared from 2- to 4-month-old virus-injected PV-Cre mice. Animals were anesthetized with isoflurane or an intraperitoneal injection of pentobarbital and then decapitated. Transverse $400 \mu \mathrm{m}$ slices were cut using a vibrating microtome (Microm HM650V). Slices were prepared in artificial CSF (aCSF) containing the following (in $\mathrm{mm}$ ): 65 sucrose, $85 \mathrm{NaCl}, 2.5 \mathrm{KCl}$, $1.25 \mathrm{NaH}_{2} \mathrm{PO}_{4}, 7 \mathrm{MgCl}_{2}, 0.5 \mathrm{CaCl}_{2}, 25 \mathrm{NaHCO}_{3}$, and 10 glucose, $\mathrm{pH}$ $7.2-7.4$ [bubbled with carbogen gas $\left(95 \% \mathrm{O}_{2} / 5 \% \mathrm{CO}_{2}\right)$ ]. Slices were immediately transferred to a storage chamber containing aCSF (in mM): $130 \mathrm{NaCl}, 3.5 \mathrm{KCl}, 1.2 \mathrm{NaH}_{2} \mathrm{PO}_{4}, 0.5 \mathrm{MgCl}_{2}, 3 \mathrm{CaCl}_{2}, 24 \mathrm{NaHCO}_{3}$, and 10 glucose, $\mathrm{pH} 7.2-7.4$, at $32^{\circ} \mathrm{C}$ (bubbled with carbogen gas until used for recording). Organotypic rat hippocampal slice cultures were prepared using a method similar to that described by Stoppini et al. (1991). Briefly, 7-d-old male Wistar rats were killed, and the brains were extracted and placed in cold $\left(4^{\circ} \mathrm{C}\right)$ Gey's balanced salt solution, supplemented with D-glucose $(34.7 \mathrm{~mm})$. The hemispheres were separated, and individual hippocampi were removed and immediately sectioned into $350-\mu \mathrm{m}$ thick slices on a McIlwain tissue chopper. Slices were rinsed in cold dissection media, placed onto Millicell-CM membranes, and maintained in culture media containing 25\% EBSS, 50\% MEM, 25\% heat-inactivated horse serum, glucose, and B27 (Invitrogen). All drugs were obtained from Tocris Biosciences and Sigma-Aldrich.

Recording conditions. Hippocampal slices were transferred to a recording chamber and continuously superfused with aCSF bubbled with carbogen gas with the same composition as the storage solution $\left(32-35^{\circ} \mathrm{C}\right.$ and perfusion speed of $2 \mathrm{ml} / \mathrm{min}$ ). Neurons within the CA3 pyramidal cell layer of the hippocampus were visualized under $20 \times$ or $60 \times$ waterimmersion objectives (Olympus) and targeted for recording. Visualization of cells was facilitated with infrared differential interference contrast or dot contrast microscopy. For the optogenetic experiments, we used epifluorescence microscopy to select slices that exhibited strong expression throughout the CA3 region. Arch-GFP experiments were only conducted in slices that exhibited widespread somatic expression in $\mathrm{PV}^{+}$ interneurons throughout the CA3 region. Whole-cell current-clamp and voltage-clamp recordings from hippocampal CA3 pyramidal neurons were performed using glass pipettes, pulled from standard wall borosilicate glass capillaries and containing the following: $110 \mathrm{~mm}$ potassium gluconate, 40 mм HEPES, 2 mm ATP-Mg, 0.3 mm Na-GTP, 4 mм NaCl, and $4 \mathrm{mg} / \mathrm{ml}$ biocytin, pH 7.2-7.3,290-300 mOsm/l osmolarity. Recordings were made using Multiclamp 700A, Multiclamp 700B, and Axoclamp 2B amplifiers and acquired using pClamp9 (Molecular Devices) or WinWCP (University of Strathclyde, Glasgow, UK) software. Gramicidin perforated-patch recordings (Kyrozis and Reichling, 1995) were performed using glass pipettes containing the following: $135 \mathrm{~mm} \mathrm{KCl,} 4 \mathrm{~mm}$ $\mathrm{Na}_{2}$ ATP, $0.3 \mathrm{~mm} \mathrm{Na} \mathrm{a}_{3} \mathrm{GTP}, 2 \mathrm{~mm} \mathrm{MgCl}, 10 \mathrm{~mm}$ HEPES, and $80 \mu \mathrm{g} / \mathrm{ml}$ gramicidin (Calbiochem), pH 7.38, $290 \mathrm{mOsm} / \mathrm{l}$ osmolarity. After obtaining a cell-attached patch, the gramicidin perforation process was evaluated by continuously monitoring the decrease in access resistance. Recordings were started once the access resistance had stabilized between 20 and $50 \mathrm{M} \Omega$ (mean $R_{\mathrm{a}} \sim 35 \mathrm{M} \Omega$ ), which usually occurred $20-40 \mathrm{~min}$ after gigaseal formation. A series resistance correction of $70 \%$ was used.

Stimulation and recording protocols. Hippocampal organotypic slices have been established as a posttraumatic model of epileptogenesis (Dyhrfjeld-Johnsen et al., 2010; Berdichevsky et al., 2012). Epileptiform activity was induced in the organotypic hippocampal slices using four different models: (1) $0 \mathrm{Mg}^{2+}$ model; (2) $0 \mathrm{Cl}^{-}$model; (3) 4-aminopyridine (4-AP) model; and (4) spontaneous model. In the $0 \mathrm{Mg}^{2+}$ model, epileptiform activity was induced by switching the perfusate to nominally $\mathrm{Mg}^{2+}$-free aCSF (in mM): $120 \mathrm{NaCl}, 3 \mathrm{KCl}, 1.2 \mathrm{NaH}_{2} \mathrm{PO}_{4}, 2$ $\mathrm{CaCl}_{2}, 23 \mathrm{NaHCO}_{3}$, and 11 glucose, $\mathrm{pH}$ 7.35-7.40. In the $0 \mathrm{Cl}^{-}$model, epileptiform activity was induced by switching the perfusate to nominally $\mathrm{Cl}^{-}$-free aCSF (in which $\mathrm{NaCl}, \mathrm{MgCl}_{2}$, and $\mathrm{CaCl}_{2}$ of standard aCSF were replaced with $120 \mathrm{~mm}$ sodium D-gluconate, $1 \mathrm{~mm} \mathrm{MgSO}_{4}$, and $3 \mathrm{~mm}$ calcium D-gluconate, respectively). In the 4-AP model, epileptiform activity was elicited by adding $50 \mu \mathrm{M} 4$-AP to the standard aCSF (Perreault and Avoli, 1992). The spontaneous model involved using hippocampal organotypic slice cultures that had been maintained for $>2$ weeks in culture and that are known to generate spontaneous epileptiform activity in standard aCSF (Dyhrfjeld-Johnsen et al., 2010; Berdichevsky et al., 2012; Lillis et al., 2012). In a subset of experiments, picrotoxin $(100 \mu \mathrm{M})$ or gabazine (SR95531 [6-Imino-3-(4-methoxyphenyl)-1(6H)-pyridazinebutanoic acid hydrobromide], $20 \mu \mathrm{M}$ ) was added to block $\mathrm{GABA}_{\mathrm{A}}$ Rs. To study epileptiform activity in acute slices, aCSF containing $0 \mathrm{~mm}$ $\mathrm{MgCl}_{2}$ and $5 \mathrm{~mm} \mathrm{KCl}$ was superfused at a speed of $6 \mathrm{ml} / \mathrm{min}$ (to facilitate sufficient delivery of oxygen and increase excitability; Hájos et al., 2009), and epileptiform activity was initiated by delivering a train of electrical stimuli via a stimulating electrode positioned in CA3 stratum pyramidale (20 pulses at $100 \mathrm{~Hz}$; Etherington and Frenguelli, 2004).

$\mathrm{GABA}_{\mathrm{A}}$ Rs were activated using a Picospritzer (General Valve; 20 psi for $20 \mathrm{~ms})$ to deliver focal "puffs" of GABA $(100 \mu \mathrm{M})$ via a patch pipette placed close to either the soma or the dendrites $(\sim 150 \mu \mathrm{m}$ from the 
soma). To prevent activation of $\mathrm{GABA}_{\mathrm{B}} \mathrm{Rs}$, the experiments were conducted in the presence of CGP55845 [(2S)-3-[(15)-1-(3,4-dichlorophenyl)ethyl] amino-2-hydroxypropyl)(phenylmethyl)phosphinic acid] (5 $\mu \mathrm{M})$. Photoactivation of ChR2 (Zhang et al., 2006) was achieved using 1-ms-duration light pulses via a diode-pumped solid-state laser (473 nm peak wavelength; Shanghai Laser \& Optics Century). The laser was coupled to a 200- or 1000- $\mu$ m-diameter mulitimode optic fiber via a collimating lens (Thorlabs). The tip of the optic fiber was positioned at an image plane in the microscope in the center of the optical axis and directed into a $20 \times / 1.0$ numerical aperture objective lens via a dichroic mirror. This resulted in a spot of light at the brain slice whose diameter was 40 or $200 \mu \mathrm{m}$, respectively, assuming zero tissue scattering. Photoactivation of Arch (Chow et al., 2010) was achieved via a wide-field, ultra-bright green LED (530 nm peak; Luxeon) placed directly under the slice chamber.

Analysis of intracellular recordings. Data were analyzed offline using custom-written programs in Igor Pro (Wavemetrics) or MATLAB (MathWorks). Postsynaptic potentials (PSPs) were defined as upward or downward deflections of $>2$ SDs from baseline. ADs were defined as large-amplitude ( $>2$ SDs above baseline noise) upward deflections of $>200 \mathrm{~ms}$ in duration in $0.1 \mathrm{~Hz}$ high-pass and $10 \mathrm{~Hz}$ low-pass filtered intracellular recordings. When using focal puffs of GABA, the value of GABA potentials was defined as the peak GABA-induced membrane potential deviation (excluding action potentials). When optically activating ChR2-expressing $\mathrm{PV}^{+}$interneurons, the value of postsynaptic GABAergic responses was defined as the average induced membrane potential deviation during a $200 \mathrm{~ms}$ period immediately after optical activation. To measure the $E_{\mathrm{GABAA}}$ during epileptiform activity, recordings were rapidly alternated between current-clamp and voltage-clamp modes. The current-clamp periods allowed the monitoring of epileptiform activity, whereas the periods in voltage clamp ( $2 \mathrm{~s}$ duration) were used to measure $E_{\mathrm{GABAA}}$ with voltage ramp protocols. Each period in voltage clamp consisted of two consecutive voltage ramps ( $500 \mathrm{~ms}$ duration, ramping from -90 to $-40 \mathrm{mV}$ ). The first ramp was applied under baseline conditions, and the second ramp was applied during activation of $\mathrm{GABA}_{\mathrm{A}}$ Rs by local application of GABA. This made it possible to construct $I-V$ plots of the holding current generated by the first ramp and the total current generated by the second ramp (reflecting the holding current plus the current through the activated $\mathrm{GABA}_{\mathrm{A}} \mathrm{Rs}$ ). $E_{\mathrm{GABAA}}$ was defined as the voltage at which the holding current and the total current intersected.

To compare $\mathrm{Cl}^{-}$accumulation in different subcellular compartments, $\mathrm{Cl}^{-}$loads were elicited by stepping the membrane voltage to different potentials for $2 \mathrm{~s}$ and activating $\mathrm{GABA}_{\mathrm{A}}$ Rs with a GABA "loading" puff directed at either the soma or the dendrite (100 ms after the start of the voltage step). Larger depolarizing voltage steps resulted in stronger driving forces on the $\mathrm{GABA}_{\mathrm{A}} \mathrm{R}$ and therefore larger $\mathrm{Cl}^{-}$loads, which were defined as the area under the $\mathrm{GABA}_{\mathrm{A}} \mathrm{R}$ current (expressed in picocoulombs), after adjusting for the holding current associated with the voltage step. Current-voltage curves were then generated by plotting the peak $\mathrm{GABA}_{\mathrm{A}} \mathrm{R}$ current as a function of holding potential, from which resting the $E_{\mathrm{GABAA}}$ was defined as the $x$-intercept value and the peak $\mathrm{GABA}_{\mathrm{A}} \mathrm{R}$ conductance $\left(g_{\mathrm{GABAA}}\right)$ as the slope. To measure the effect of $\mathrm{Cl}^{-}$loads on $E_{\mathrm{GABAA}}$, a second "test" puff was then delivered $100 \mathrm{~ms}$ after the end of the voltage step and therefore $2 \mathrm{~s}$ after the first GABA puff. To estimate $E_{\text {GABAA }}$ from the test puff, we assumed a constant $g_{\text {GABAA }}$ across the two GABA puffs and used the resting $E_{\mathrm{GABAA}}$ and $g_{\mathrm{GABAA}}$ (calculated as described above) to solve the following equation:

$$
\mathrm{GABA}_{\mathrm{A}} \mathrm{R} \text { current }=g_{\mathrm{GABAA}}\left(\text { holding potential }-E_{\mathrm{GABAA}}\right) .
$$

To assess the degree of synchronous activity, Pearson's correlation coefficients were calculated from simultaneous current-clamp recordings in two CA3 pyramidal neurons. Recording epochs were compared during the period before epileptiform activity, the tonic phase, the $\mathrm{AD}$ phase, and the period after the epileptiform activity. Correlation coefficients were calculated across $8 \mathrm{~s}$ time windows in each case, except for the tonic phase in acute slice recordings in which the entire phase was used (mean duration, $2.0 \pm 0.3 \mathrm{~s} ; n=17$ ).
Modeling. To investigate the effects of estimating $E_{\mathrm{GABAA}}$ from somatic recordings, a multicompartmental model of a rat CA1 hippocampal pyramidal neuron at postnatal day 14 was constructed in the NEURON simulation environment (Carnevale and Hines, 2006). The morphology of the neuron was sourced from NeuroMorpho.Org (Ascoli, 2006) and based on a reconstruction performed by Scorza et al. (2011) (NeuroMorpho.Org identification number NMO_07263). Model parameters were assigned as follows: (1) membrane capacitance, $C_{\mathrm{m}}=1 \mu \mathrm{F} / \mathrm{cm}^{2}$; (2) axial resistance, $R_{\mathrm{a}}=150 \Omega / \mathrm{cm}$; (3) passive membrane reversal potential, $e_{\mathrm{pas}}$ $=-70 \mathrm{mV}$; and (4) passive membrane conductance, $g_{\text {pas }}=61.0 \mu \mathrm{S} /$ $\mathrm{cm}^{2}$. This equated to a total input resistance $\left(R_{\mathrm{i}}\right)$ of $233 \mathrm{M} \Omega$, as measured by simulated voltage clamp at the soma and that matched the experimentally observed $R_{\mathrm{i}}$ recorded under baseline conditions $(233.1 \pm 23.7 \mathrm{M} \Omega$, $n=8$; see Fig. $3 D-F)$. To simulate a drop in $R_{\mathrm{i}}$ during the AD phase, $g_{\text {pas }}$ was increased to $157.2 \mu \mathrm{S} / \mathrm{cm}^{2}$, which equated to an $R_{\mathrm{i}}$ of $110 \mathrm{M} \Omega$ and matched the experimentally observed $R_{\mathrm{i}}$ recorded during the putative $\mathrm{AD}$ phase $(110.3 \pm 6.6 \mathrm{M} \Omega, n=8$; see Fig. $3 D-F)$. Activation of $\mathrm{GABA}_{\mathrm{A}}$ Rs via a GABA puff was simulated by placing $20 \mathrm{GABA}_{\mathrm{A}} \mathrm{R}-$ containing synapses within a $10 \mu \mathrm{m}$ radius of either the center of the soma ("simulated somatic GABA") or within a $10 \mu \mathrm{m}$ radius of a point on the apical dendrite, $150 \mu \mathrm{m}$ from the soma ("simulated dendritic GABA"). The GABA response was simulated by using an alpha function with a tau of $250 \mathrm{~ms}$, and the cumulative peak conductance of all 20 GABA synapses (whether at the soma or dendrite) was set to $9.09 \mathrm{nS}$, reflecting the fact that the experimentally measured peak GABA conductance when puffing over the soma was $9.09 \pm 1.35 \mathrm{nS}(n=8$; see Fig. $3 D-F)$. No active conductances were included in the model. To recreate the experimental measurements of $E_{\mathrm{GABAA}}$, a simulated voltage clamp was placed at the soma of the modeled neuron, and two consecutive voltage ramps were then applied: one before and one during the simulated activation of $\mathrm{GABA}_{\mathrm{A}}$ Rs. The resulting traces were then used to construct $I-V$ plots, and $E_{\mathrm{GABAA}}$ was defined in the same way as for the experimental recordings (see above).

To simulate the effect of compartment size on intracellular $\mathrm{Cl}^{-}$concentration $\left[\mathrm{Cl}^{-}\right]_{\mathrm{i}}$ changes, a single-compartment model was generated in MATLAB (MathWorks). This compartment was modeled as a cylinder with a length of $50 \mu \mathrm{m}$. The volume of the cylinder was altered by adjusting its radius from 1 to $10 \mu \mathrm{m}$. Initial $\left[\mathrm{Cl}^{-}\right]_{\mathrm{i}}$ was set to $4.0 \mathrm{~mm}$, equivalent to an initial $E_{\mathrm{GABAA}}$ of $-80 \mathrm{mV}$. Cl ${ }^{-}$loads of between 0 and $400 \mathrm{pC}$ were applied, and the resulting change in $\left[\mathrm{Cl}^{-}\right]_{\mathrm{i}}$ was determined. $\mathrm{No} \mathrm{Cl}^{-}$ extrusion mechanisms were included in the model.

Histological analyses. After intracellular recording, the slices were fixed overnight in $4 \%$ paraformaldehyde and $15 \%$ saturated picric acid in $0.1 \mathrm{M}$

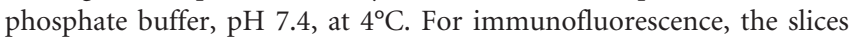
were washed and embedded in 5\% agar and resectioned at $50 \mu \mathrm{m}$ on a vibrating microtome (VT1000S; Leica). All sections were preincubated in $10-20 \%$ normal donkey serum (NDS; Vector Laboratories) in PBS for $>1 \mathrm{~h}$ at room temperature. Biocytin-filled cells were visualized by incubating sections in 1:10,000 streptavidin-405 conjugate (Invitrogen) in PBS containing $0.3 \%$ Triton X-100 (PBS-Tx) overnight at $4^{\circ} \mathrm{C}$. YFP expression was visualized by incubating sections in 1:1000 chicken antiGFP (Aves Labs) in PBS-Tx and 1\% NDS overnight at $4^{\circ} \mathrm{C}$, followed by 1:500 donkey anti-chicken-488 fluophore (Jackson ImmunoResearch) in PBS-Tx for $2 \mathrm{~h}$ at room temperature. Finally, all sections were mounted in Vectashield (Vector Laboratories), and images were captured with an LSM 710 (Zeiss) confocal microscope using ZEN software (Zeiss) or Leica DM5000B epifluorescence microscope using Openlab software (PerkinElmer Life and Analytical Sciences). For DAB immunocytochemistry, the slices were processed using standard protocols, and images of biocytin-filled cells were captured with a Leica DM5000B microscope. The distance between pairs of DAB-labeled CA3 pyramidal neurons was measured as the linear distance between the center of their somata.

Statistics. All data are presented as means \pm SEMs. Student's $t$ test were performed using SPSS 17.0 (IBM SPSS statistics) or GraphPad Prism version $5.0\left(\right.$ GraphPad Software; $\left.{ }^{\star} p<0.05,{ }^{* *} p<0.01,{ }^{* *} p<0.001\right)$. 
A
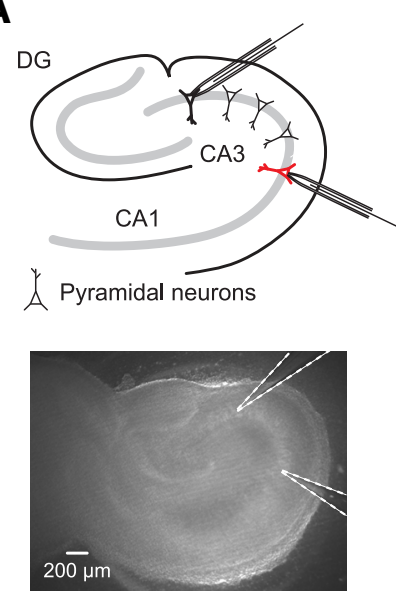

D

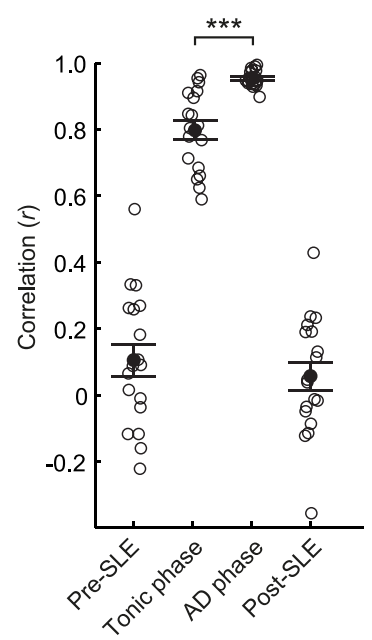

B

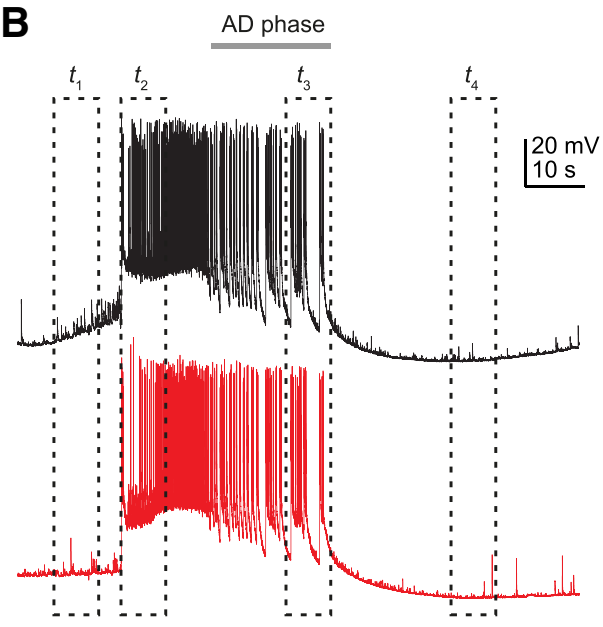

E

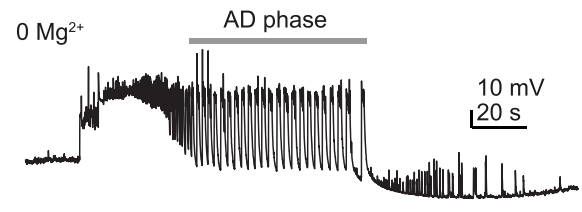

$0 \mathrm{Cl}^{-}$

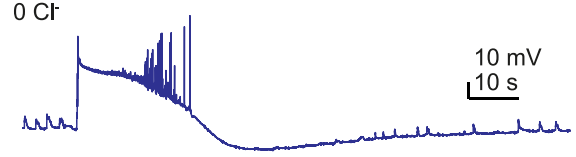

$0 \mathrm{Mg}^{2+}+$ picrotoxin

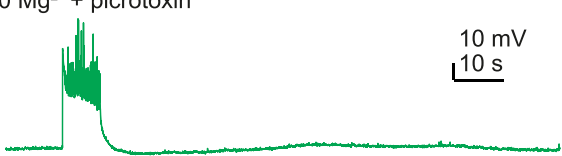

C

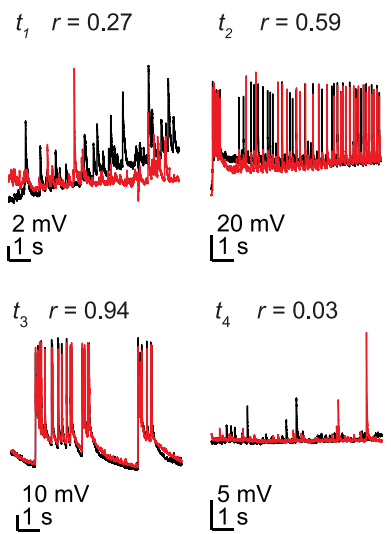

$\mathbf{F}$

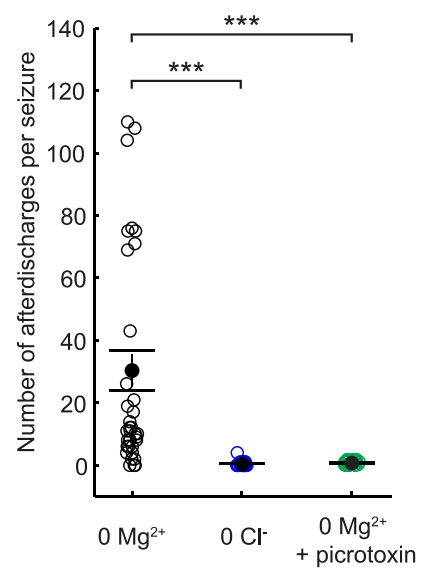

Figure 1. Synchronous ADs depend on GABAergic transmission. $A$, Diagram of the experimental setup (top), which involved simultaneous whole-cell patch-clamp recordings from two pyramidal neurons at either end of the CA3 region of an organotypic hippocampal brain slice. Image of a slice (bottom) showing the location of the two CA3 pyramidal neurons targeted for recording. $B$, Dual whole-cell current-clamp recordings of an SLE induced by removing $\mathrm{Mg}^{2+}$ from the slice perfusate $\left(0 \mathrm{Mg}^{2+}\right.$ seizures). Four epochs representing the pre-SLE period $\left(t_{1}\right)$, tonic phase $\left(t_{2}\right)$, AD phase $\left(t_{3}\right)$, and post-SLE period $\left(t_{4}\right)$ are denoted by dashed rectangles. $C$, Insets show the four epochs in $\boldsymbol{B}$, with recordings from the two neurons superimposed to reveal the extent of synchronous activity. The Pearson's coefficient $(r)$ was calculated from a direct linear correlation of the two raw traces during each epoch ( $8 \mathrm{~s}$ duration). The values demonstrate that the degree of correlation increased significantly during the SLE and peaked during the AD phase. $\boldsymbol{D}$, Population data showing a significant increase in correlated activity between pairs of CA3 pyramidal neurons during the AD phase compared with the tonic phase of $0 \mathrm{Mg}^{2+}$-induced seizures $\left({ }^{* *} p<0.001, t\right.$ test). $\boldsymbol{E}$, Representative current-clamp recordings from CA3 pyramidal neurons during epileptiform activity evoked under three different conditions: (1) a $0 \mathrm{Mg}^{2+} \mathrm{SLE}$ (top, black trace); (2) an SLE elicited by removing $\mathrm{Cl}^{-}$from the aCSF $\left(0 \mathrm{Cl}^{-} \mathrm{SLE}\right.$; middle, blue trace); and (3) an SLEe elicited in $0 \mathrm{Mg}{ }^{2+}+$ picrotoxin (bottom, green trace). Note that the latter two SLEs lack ADs. $F$, Models of epileptiform activity that reduce or abolish GABAergic signaling lack ADs ${ }^{* * *} p<0.001, t$ test).

\section{Results}

\section{Highly synchronous epileptiform ADs in the hippocampus} depend on GABAergic transmission

Epilepsy is characterized by periods of hypersynchronous, hyperexcitability within brain networks (Jiruska et al., 2013). To investigate the cellular basis of hypersynchronous activity during epileptiform activity in the hippocampus, we performed dual whole-cell current-clamp recordings from pairs of pyramidal neurons in the $\mathrm{CA} 3$ region of hippocampal organotypic slices and induced epileptiform activity by removing $\mathrm{Mg}^{2+}$ from the slice perfusate (Anderson et al., 1986; Mody et al., 1987; Gutiérrez et al., 1999; Avoli et al., 2002; Fig. 1A). In accordance with previous studies, the resulting epileptiform activity displayed a characteristic tonic-clonic structure. The tonic phase was characterized by a strong and sustained depolarization of the membrane potential $(>40 \mathrm{mV})$, on which occurred high-frequency, low-amplitude discharges (Fig. $1 B, C, E$ ). This then transitioned into the clonic or
AD phase (Higashima et al., 1996; Trevelyan et al., 2007a; Isomura et al., 2008), which was characterized by a relatively hyperpolarized membrane potential with overlying high-amplitude rhythmic bursts (i.e., ADs), each lasting $>200 \mathrm{~ms}$. We refer to the period of activity encompassing both the tonic and $\mathrm{AD}$ phase as the seizure-like event (SLE).

Our dual recordings enabled us to assess the degree of synchronization during epileptiform activity. Using linear correlation as a measure of synchronization (Jiruska et al., 2013), we compared (1) the pre-seizure period before the SLE had initiated, (2) the tonic phase of the SLE, (3) the AD phase, and (4) the post-seizure period after the SLE had ended (Fig. $1 B, C$ ). Consistent with previous work, the correlation and hence synchrony observed during the tonic and $\mathrm{AD}$ phases were markedly increased compared with pre- and post-SLE levels (pre-SLE, $r=$ $0.10 \pm 0.05$; tonic, $r=0.80 \pm 0.03 ; \mathrm{AD}, r=0.95 \pm 0.01$; and post-SLE, $r=0.06 \pm 0.04 ; p<0.001$, paired $t$-tests, $n=18$; Fig. 
A

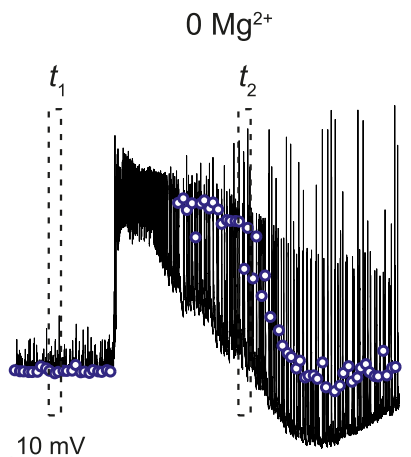

$200 \mathrm{~s}$

B

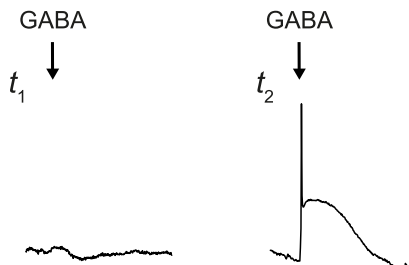

$0.5 \mathrm{~s}$

$5 \mathrm{mV}$

C

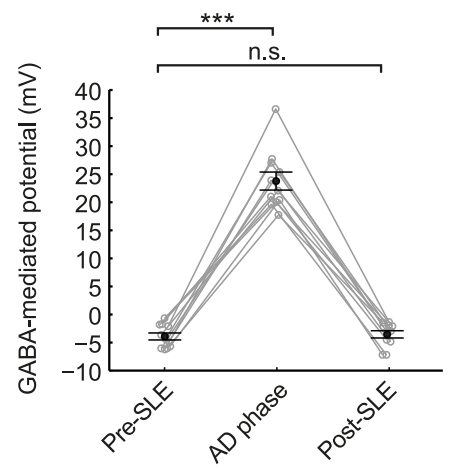

4-AP
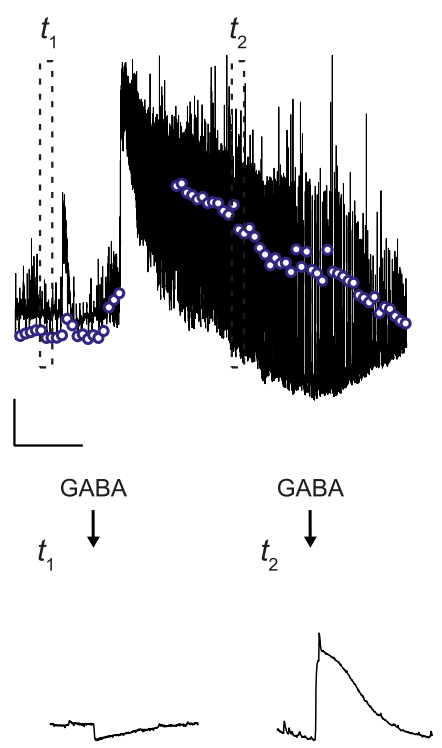

L

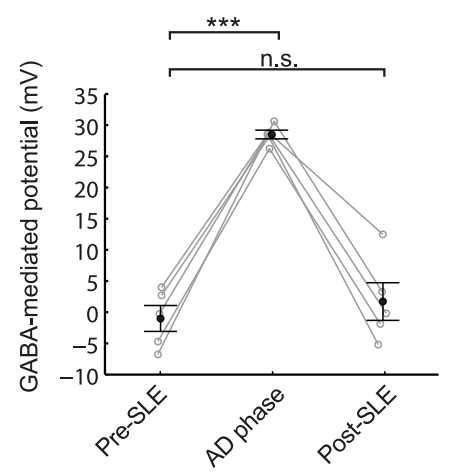

Spontaneous
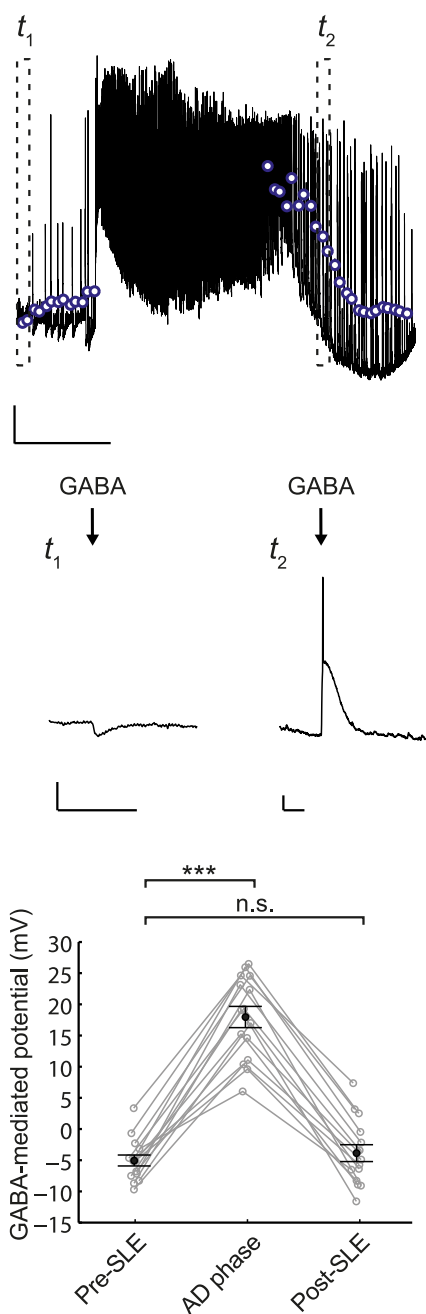

Figure 2. Transient depolarizing shifts in postsynaptic GABAergic signaling are a general feature of epileptiform activity. $A$, The postsynaptic response to $G_{A B A} R_{A} R$ activation was investigated in three in vitro models of epileptiform activity: (1) a $0 \mathrm{Mg}^{2+}$ model (left); (2) a 4-AP model (middle); and (3) a spontaneous model (right). Gramicidin perforated patch-clamp recordings in current-clamp mode were made from CA3 pyramidal neurons, and $G_{A B A} R$-mediated responses were elicited every $10 \mathrm{~s}$ by delivering a puff of $G A B A(100 \mu \mathrm{m})$ to the cell soma. When individual responses to GABA could be clearly identified on the background activity, the effect on the membrane potential was calculated and defined as the GABA-mediated potential (blue circles). Note how GABA-mediated potentials became depolarizing during all three models of epileptiform activity. $\boldsymbol{B}$, Representative GABA-mediated potentials corresponding to the dashed boxes in $\boldsymbol{A}$. In many cases, the depolarizing effect of the $G A B A$ puff was sufficient to generate action potentials. $C$, Population data demonstrate that $G A B A_{A} R$ activation had a pronounced depolarizing effect on the membrane potential during the $A D$ phase $\left({ }^{* * *} p<0.001\right.$, paired $t$ test $)$.

$1 C, D)$. Furthermore, the degree of correlated activity was observed to increase as the epileptiform activity progressed, with the level of correlation reaching its highest levels during the $\mathrm{AD}$ phase and being significantly greater than during the tonic phase $(r=$ 0.95 vs $0.80 ; p<0.001$, paired samples $t$ test). Therefore, the AD activity that constitutes the clonic phase represents a particularly synchronous form of network activity that emerges during epileptiform activity.

GABAergic transmission has been shown to play a central role in the synchronization of neuronal activity during physiological and pathological network states (Michelson and Wong, 1991; Cobb et al., 1995; Klausberger et al., 2003; Aradi and Maccaferri, 2004; Zsiros et al., 2007; Ellender et al., 2010). To test whether GABAergic transmission plays an important role during the highly synchronous $\mathrm{AD}$ phase, we examined two models in which GABAergic signaling was disrupted. First, $G_{A B A}$ Rs were blocked with picrotoxin $(100 \mu \mathrm{M})$ during the induction of epileptiform activity with the $0 \mathrm{Mg}^{2+}$ model. Second, epileptiform activity was induced using a $0 \mathrm{mM} \mathrm{Cl}^{-}$model in which the driving force for $\mathrm{GABA}_{\mathrm{A}} \mathrm{Rs}$ is removed by eliminating $\mathrm{Cl}^{-}$from the aCSF (Yamamoto and Kawai, 1967; Chamberlin and Dingledine, 1988). Both of these models resulted in shorter SLEs that almost entirely lacked $\mathrm{ADs}\left(0 \mathrm{Mg}^{2+}\right.$ model, $30.3 \pm 6.2 \mathrm{ADs}$ per SLE, $n=$ $36 ; 0 \mathrm{Mg}^{2+}$ model $+100 \mu \mathrm{M}$ picrotoxin, $0.7 \pm 0.1$ ADs per SLE, $n=26 ; 0 \mathrm{Cl}^{-}$model, $0.4 \pm 0.2 \mathrm{ADs}$ per SLE, $n=31 ; p<0.001$, $t$ tests; Fig. $1 E, F)$. We next set out to determine how GABAergic activity might contribute to the generation of highly synchronous ADs.

\section{GABAergic transmission becomes excitatory during the AD} phase of epileptiform activity

Strong activation of $\mathrm{GABA}_{\mathrm{A}}$ Rs can lead to intracellular $\mathrm{Cl}^{-}$accumulation and a change in the driving force for $\mathrm{GABA}_{\mathrm{A}} \mathrm{Rs}$ (Staley and Proctor, 1999). To examine potential changes in GABAergic transmission during the $\mathrm{AD}$ phase of hippocampal seizure activity, we performed gramicidin perforated patchclamp recordings from the soma of CA3 pyramidal neurons dur- 
A

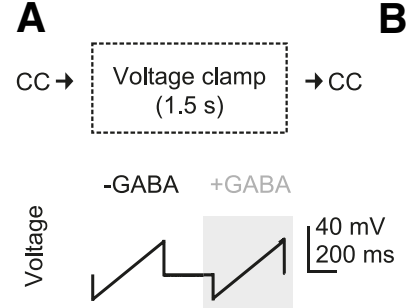

B

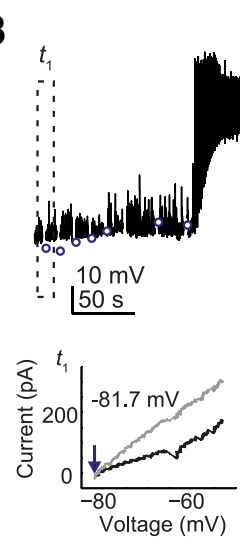

E

D

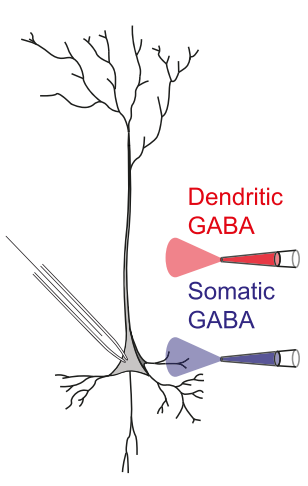

G

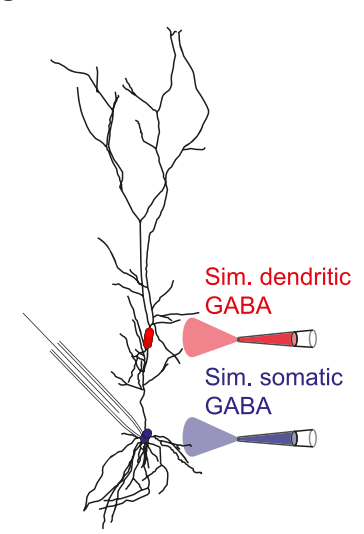

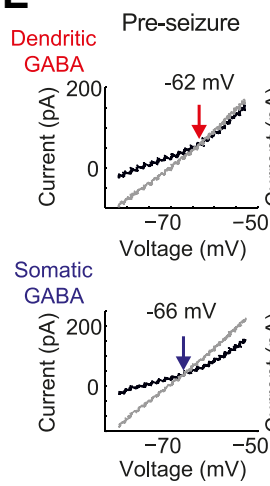

H Sim. som. GABA

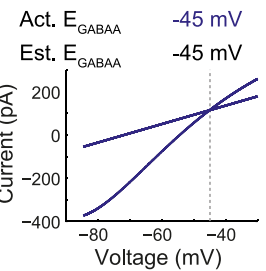

ऐ -60

希

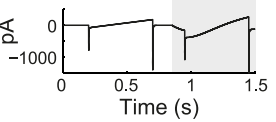

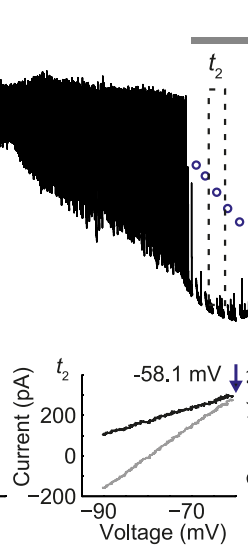

TTX

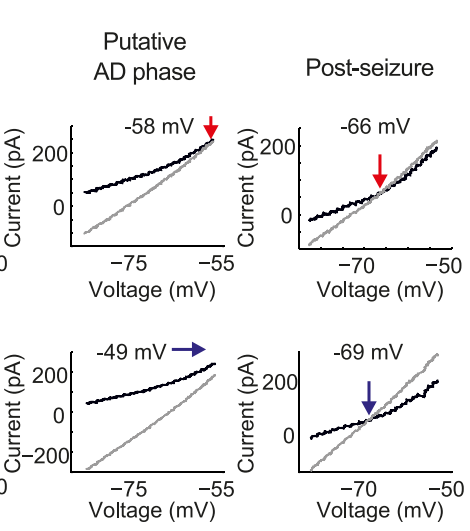

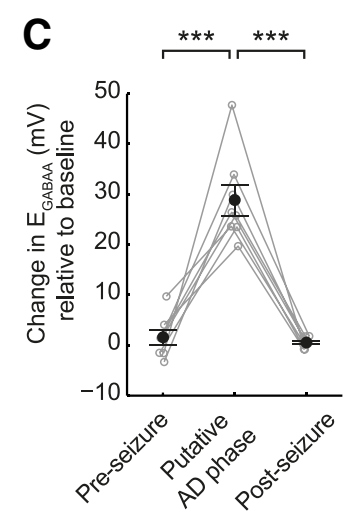

F

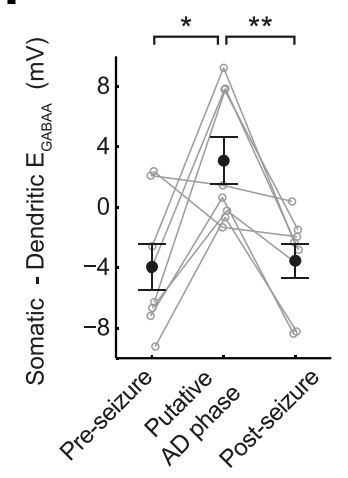

Sim. dend. GABA

$-45 \mathrm{mV}$

$-40 \mathrm{mV}$

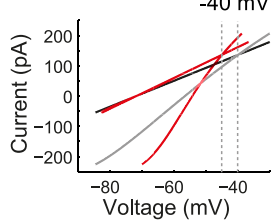

+Sim. GABA

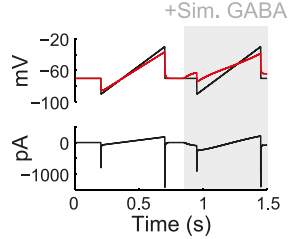

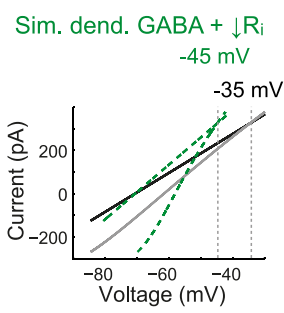

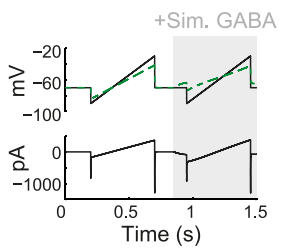

I

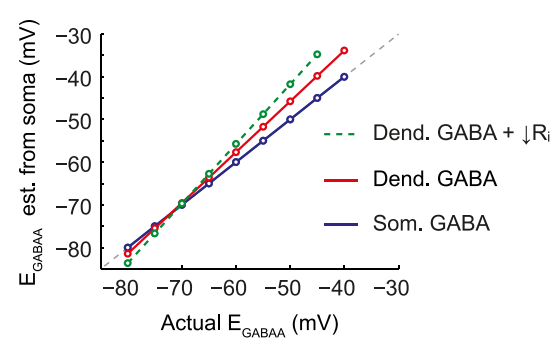

Figure 3. Epileptiform activity causes a transient depolarizing shift in $E_{G A B A A}$ that is most pronounced at the somatic compartment. $A$, To measure $E_{\text {GABAA }}$ during epileptiform activity, gramicidin perforated patch-clamp recordings were performed and the mode was rapidly switched from current-clamp (CC) to brief periods in voltage clamp (1.5 s duration) every $10 \mathrm{~s}$. While in voltage clamp, two consecutive voltage ramps were applied: (1) the first without GABA application (-GABA); and (2) the second paired with GABA application (+GABA; see Materials and Methods). B, A representative recording from a $C A 3$ pyramidal neuron (top) in which $E_{G A B A A}$ was estimated during the $A D$ phase. To eliminate the effects of ongoing spiking activity on $E_{G A B A A}$ measurements, $T$ TTX $(1 \mu \mathrm{M})$ was applied after SLE onset (horizontal gray bar). Because this blocked ADs, we refer to this as the putative AD phase. $E_{G A B A A}$ values are indicated by the blue circles, and the dashed boxes highlight periods during the pre-SLE period $\left(t_{1}\right)$, putative AD phase $\left(t_{2}\right)$, and post-SLE period $\left(t_{3}\right) . I-V$ plots (bottom) were used to define $E_{\text {GABAA }}$ as the voltage at which the holding current (from the first ramp; black line) and the total current (from the second ramp and reflecting the holding current plus the current through $\mathrm{GABA}_{\mathrm{A}} \mathrm{Rs}$; gray line) intersect. Note that (Figure legend continues.) 
ing $0 \mathrm{Mg}^{2+}$-induced epileptiform activity. This recording configuration avoids disruption of the $\left[\mathrm{Cl}^{-}\right]_{\mathrm{i}}$ of the neuron (Kyrozis and Reichling, 1995). The membrane potential was measured in current-clamp mode, and $\mathrm{GABA}_{\mathrm{A}}$ Rs were activated by delivering brief puffs of GABA $(100 \mu \mathrm{M})$ to the soma of the recorded neuron every $10 \mathrm{~s}$ in the presence of a $\mathrm{GABA}_{\mathrm{B}}$ receptor antagonist (CGP55845, $5 \mu \mathrm{M}$ ). GABA-mediated potentials were defined as the change in membrane potential after $G_{A B A} R$ activation (excluding action potentials) relative to resting membrane potential before SLE onset. Before the start of SLEs, GABAmediated potentials were hyperpolarizing compared with the resting membrane potential, with a mean value of $-3.9 \pm 0.6 \mathrm{mV}$ $(n=11)$. However, during the AD phase of SLEs, GABAmediated potentials became significantly depolarizing (23.8 \pm $1.6 \mathrm{mV}, p<0.001$, paired samples $t$ test, $n=11$ ). Indeed, during the $\mathrm{AD}$ phase, $\mathrm{GABA}_{\mathrm{A}} \mathrm{R}$ activation could independently generate action potentials, revealing that $E_{\mathrm{GABAA}}$ exceeded the action potential threshold (Fig. $2 B$ ). This recovered in the post-SLE period when $\mathrm{GABA}_{\mathrm{A}} \mathrm{R}$ potentials returned to pre-SLE levels $(-3.5 \pm 0.6$ $\mathrm{mV}$; Fig. $2 A-C$, left).

A similar SLE-induced depolarizing shift in GABAergic transmission was observed in two additional in vitro models of seizure activity: (1) the 4-AP model in which the voltage-gated $\mathrm{K}^{+}$channel antagonist 4-AP $(50 \mu \mathrm{M})$ was added to the bath solution (Perreault and Avoli, 1992); and (2) the spontaneous model in which hippocampal organotypic slices are maintained in culture until they spontaneously generate epileptiform activity in standard

\footnotetext{
(Figure legend continued.) $E_{\mathrm{GABA}}$ was at hyperpolarized values in the pre-SLE period, switched to depolarizing values during the putative $A D$ phase, before eventually recovering post-SLE. $C$, Population data showing that $E_{\mathrm{GABA}}$ is significantly more depolarized during the putative $A D$ phase than during the pre-SLE or post-SLE periods ( ${ }^{* * *} p<0.001$, paired $t$ test). $\boldsymbol{D}$, Using a similar recording configuration, $S \mathrm{LE}$-induced depolarizing shifts in $E_{\mathrm{GABA}}$ were compared along the somatodendritic axis of CA3 pyramidal neurons by locally applying GABA to either the dendritic (red) or somatic (blue) compartment. $\boldsymbol{E}$, I-V plots in which dendritic (top) and somatic (bottom) $E_{\text {GABAA }}$ was measured during the pre-SLE period (left), putative AD phase (middle), and post-SLE period (right). Note that, during the putative AD phase, both somatic and dendritic $E_{G A B A A}$ had become depolarizing but that the $E_{\text {GABAA }}$ shift was greater at the soma. $F$, Population data showing that $S L E-$-induced depolarizing shifts in $E_{G A B A A}$ are more pronounced at the soma. Somatic $E_{G A B A A}$ tends to be more negative than dendritic $E_{G A B A A}$ in the pre- and post-seizure periods, but this relationship is inverted during the putative AD phase ( ${ }^{*} p<0.05$ and ${ }^{* *} p<$ 0.01 , paired $t$ test). $\mathbf{G}$, A multicompartmental model of a rat hippocampal pyramidal neuron with $G_{A B A_{A}} R$ s at the soma (blue circles) and dendrite (red circles) was generated in the NEURON simulation environment and used to assess the effect of estimating dendritic $E_{\text {GABAA }}$ from somatic recordings. $\boldsymbol{H}$, To parallel the experimental recordings, $E_{G A B A A}$ was calculated from voltage ramp protocols delivered to the soma of the model neuron before and during the simulated activation of $G A B A_{A}$ Rs. The simulated GABA conductance was delivered to the soma (left), to the dendrite under baseline conditions (middle; $R_{\mathrm{i}}=233 \mathrm{~m} \Omega$ ), or to the dendrite when the $R_{\mathrm{i}}$ was reduced to match that observed during the AD phase (right; $R_{\mathrm{i}}=110 \mathrm{~m} \Omega$ ). In the example shown, $E_{\text {GABAA }}$ was set to $-45 \mathrm{mV}$ throughout the somatic and dendritic compartments. The traces (bottom) show the membrane potential and current recorded from the soma of the model neuron (black traces) and the membrane potential actually achieved in the compartment where the simulated GABA conductance was delivered (colored traces). Note that, for somatic GABA, the membrane potential shows no space clamp error (left; blue trace overlaps black trace). In contrast, a voltage ramp in the soma is not able to fully clamp the dendrite (middle; red trace), and this is accentuated when the $R_{\mathrm{i}}$ is reduced (right; green trace). The effects on estimates of $E_{\text {GABAA }}$ are illustrated in the corresponding I- $V$ plots (top). In each case, the intersection of the gray and black lines indicates the $E_{\text {GABAA }}$ estimated from the soma, whereas the intersection of the colored traces shows the actual $E_{G A B A A}$ in the relevant compartment (i.e., after accounting for space clamp). Note that, for the somatic GABA (left), the estimate of $E_{G A B A A}$ overlaps with the actual $E_{\mathrm{GABAA}}$. In contrast, estimates of dendritic $E_{\mathrm{GABAA}}$ from the soma are more depolarized than the actual $E_{G A B A A}$ (middle), and this is accentuated when $R_{\mathrm{i}}$ decreases (right). $I$, For depolarized $E_{G A B A A}$ values, estimates of dendritic $E_{G A B A A}$ made from the soma are more depolarized than the actual dendritic $E$.
}

aCSF (Dyhrfjeld-Johnsen et al., 2010; Berdichevsky et al., 2012; Lillis et al., 2012). For the 4-AP model, $\mathrm{GABA}_{\mathrm{A}} \mathrm{R}$ potentials shifted from $-1.0 \pm 2.1 \mathrm{mV}$ in the pre-SLE period to $28.5 \pm 0.7 \mathrm{mV}$ during the $\mathrm{AD}$ phase $(p<0.001, n=5)$. Meanwhile, for spontaneously generated SLEs, $\mathrm{GABA}_{\mathrm{A}} \mathrm{R}$ potentials shifted from $-5.0 \pm 0.9 \mathrm{mV}$ during the pre-SLE period to $18.0 \pm 1.7 \mathrm{mV}(p<0.001, n=15)$ during the $\mathrm{AD}$ phase (Fig. $2 A-C$, middle and right). This demonstrates that pronounced depolarizing shifts in $\mathrm{GABA}_{\mathrm{A}} \mathrm{R}$ potentials are a general feature of the $\mathrm{AD}$ phase during epileptiform activity.

\section{Epileptiform activity causes transient depolarizing shifts in $E_{\mathrm{GABAA}}$ that are most pronounced within the somatic compartment of pyramidal neurons}

To confirm that the depolarizing GABAergic potentials observed during the $\mathrm{AD}$ phase were attributable to a transient collapse in the driving force for the $\mathrm{GABA}_{\mathrm{A}} \mathrm{R}$, we used gramicidin recordings to perform measurements of $E_{\mathrm{GABAA}}$ during epileptiform activity. The recording configuration was rapidly switched between current-clamp mode and brief periods in voltage-clamp mode, during which a voltage ramp protocol was used to generate a rapid estimate of $E_{\text {GABAA }}$ (Fig. 3A). Because large membrane potential changes interfered with the estimate of $E_{\mathrm{GABAA}}$, measurements were made immediately after the tonic phase or in SLEs in which the ADs were abolished by fast superfusion of tetrodotoxin (TTX; $1 \mu \mathrm{M}$ ). Therefore, we refer to our $E_{\mathrm{GABAA}}$ measurements as relating to the putative AD phase. As shown in Figure 3, $B$ and $C$, epileptiform activity produced a pronounced shift in $E_{\mathrm{GABAA}}$ of $28.8 \pm 3.1 \mathrm{mV}$ $(p<0.001 ; n=8)$ during the putative $\mathrm{AD}$ phase. Within $60-80 \mathrm{~s}$ after SLE offset, $E_{\mathrm{GABAA}}$ had recovered to baseline levels ( $p=0.3$ compared with pre-SLE levels, $t$ test). Because intracellular $\mathrm{Cl}^{-}$is the major determinant of $E_{\mathrm{GABAA}}$, the observed depolarizing shift in $E_{\text {GABAA }}$ is consistent with an SLE-induced accumulation of intracellular $\mathrm{Cl}^{-}$that is evident during the $\mathrm{AD}$ phase.

Hippocampal pyramidal neurons receive GABAergic synaptic input across their somatodendritic axis (Klausberger and Somogyi, 2008). To determine whether SLE-induced shifts in $\mathrm{GABA}_{\mathrm{A}} \mathrm{R}$ signaling might differ between subcellular compartments, we performed gramicidin perforated patch-clamp experiments in which we selectively activated either somatic or dendritic $\mathrm{GABA}_{\mathrm{A}}$ Rs. By rapidly switching from current-clamp to voltageclamp mode and by puffing GABA at two independent locations on the postsynaptic neuron, $E_{\mathrm{GABAA}}$ could be calculated at both somatic and dendritic locations $(\sim 150 \mu \mathrm{m}$ from the soma; Fig. $3 D, E)$. The SLE-induced depolarizing shift in $E_{\mathrm{GABAA}}$ was more pronounced in the somatic compartment than in the dendritic compartment of CA3 hippocampal pyramidal neurons. Although both compartments experienced a depolarizing shift in $E_{\text {GABAA }}$ (Fig. $3 E$ ), the shift in $E_{\mathrm{GABAA}}$ during the putative $\mathrm{AD}$ phase was $7.1 \pm 1.6 \mathrm{mV}$ greater at the soma than at the dendrites $(p<0.01 ; n=8$; Fig. $3 F)$. This somatodendritic difference cannot be accounted for by space-clamp effects associated with somatic voltage-clamp recordings. Computer simulations using a multicompartmental model of a rat hippocampal pyramidal neuron (Fig. 3G; see Materials and Methods) demonstrated that, for measurements made from the soma, depolarized dendritic $E_{\text {GABAA }}$ values tend to be overestimated in terms of the degree of depolarizing shift and that this effect increases when the $R_{\mathrm{i}}$ of a neuron drops, as occurs during the putative $\mathrm{AD}$ phase (Fig. $3 \mathrm{H}, \mathrm{I}$; see Materials and Methods). Therefore, our observed somatodendritic difference in $E_{\mathrm{GABAA}}$ shifts is best explained by either increased activity of soma-targeting GABAergic inputs during SLEs or biophysical differences in compartment susceptibility to $\mathrm{Cl}^{-}$loads. 


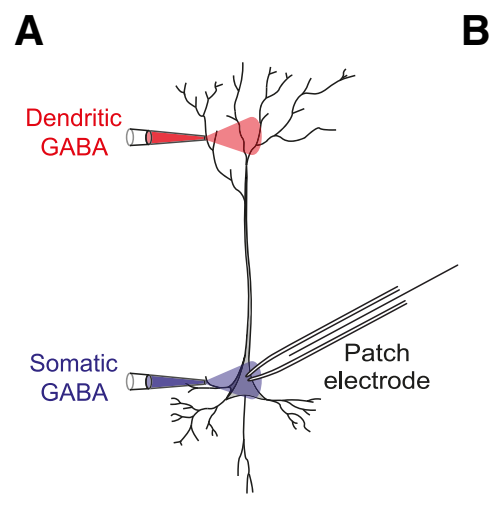

D

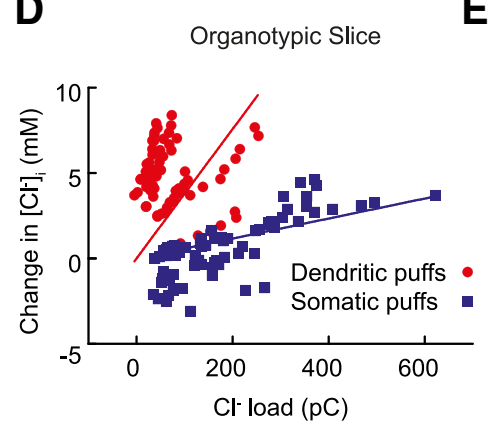

E
B
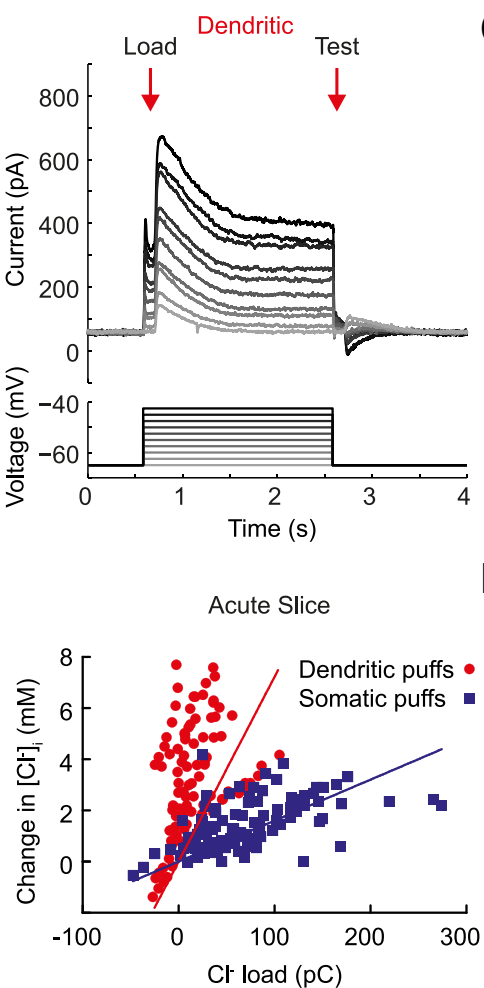

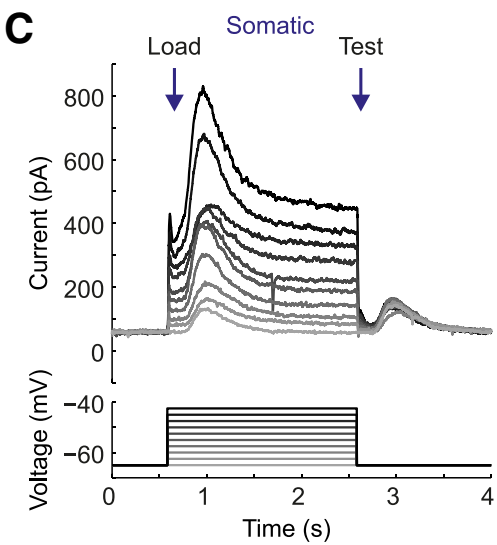

$\mathbf{F}$

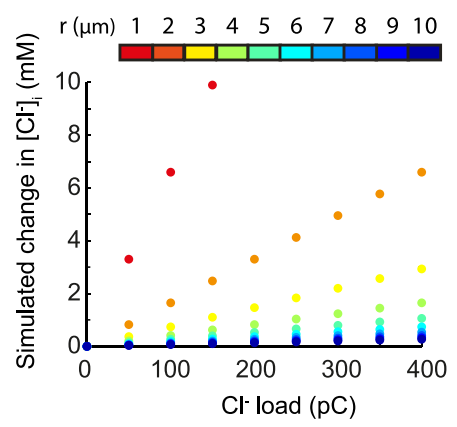

Figure 4. Because of their larger volume, the somatic compartments of neurons are more resistant to $\mathrm{Cl}^{-}$accumulation than dendritic compartments. $A$, Gramicidin voltage-clamp recordings from hippocampal CA3 pyramidal neurons in which $\mathrm{GABA}_{A}$ Rs were activated by puffing $100 \mu \mathrm{m} \mathrm{GABA}$ to either the dendritic compartment (red) or somatic compartment (blue). Different sized Cl ${ }^{-}$ loads were elicited by depolarizing the membrane potential (for $2 \mathrm{~s}$ in increasing $2.5 \mathrm{mV}$ depolarizing steps) and simultaneously activating $G A B A_{A} R s$ (100 ms after the start of the step). Larger depolarizing voltage steps resulted in stronger driving forces on the $\mathrm{GABA}_{A} R$ and therefore larger $\mathrm{Cl}^{-}$loads. At $100 \mathrm{~ms}$ after the end of the voltage step (and therefore $2 \mathrm{~s}$ after the loading $\mathrm{GABA}$ puff), a second test GABA puff was delivered to estimate whether $E_{\mathrm{GABAA}}$ had changed. $\boldsymbol{B}$, When the puffer pipette was positioned over the dendritic compartment, increasing amounts of $\mathrm{Cl}^{-}$loaded by the first puff affected the size and direction of $\mathrm{GABA}_{A} \mathrm{R}$ currents to the test puff. $\boldsymbol{C}$, This effect was not as evident when similar $\mathrm{Cl}^{-}$loads were generated at the somatic compartment. $\boldsymbol{D}$, Population data from organotypic hippocampal slices showed that the dendritic compartment of hippocampal pyramidal neurons is more susceptible to a $\mathrm{Cl}^{-}$load than the somatic compartment. $\boldsymbol{E}_{\text {, A similar }}$ relationship between the dendritic and somatic compartments was evident in acute slices. $\boldsymbol{F}$, A single-compartment model was used to simulate the effect of compartment volume on $\mathrm{Cl}^{-}$ accumulation. The compartment was modeled as a cylinder with a length of $50 \mu \mathrm{m}$ and radius varying from 1 to $10 \mu \mathrm{m}$. Smaller-volume compartments (warmer colors) resulted in larger increases in $\left[\mathrm{Cl}^{-}\right]_{\mathrm{i}}$ for a given $\mathrm{Cl}^{-}$load.

\section{Compared with the soma, dendrites are intrinsically more prone to $\mathrm{Cl}^{-}$accumulation and a collapse in $E_{\mathrm{GABA}}$}

To investigate whether subcellular compartments of a neuron differ in their ability to deal with an exogenous $\mathrm{Cl}^{-}$load, we performed gramicidin perforated patch-clamp recordings from hippocampal pyramidal cells while GABA was locally applied by puffer pipette either to the soma or the dendrites (Fig. 4A). An initial loading GABA puff was followed by a subsequent test GABA puff (both $20 \mathrm{~ms}$ ). The amount of $\mathrm{Cl}^{-}$entering the cell during the loading puff could be varied by changing the membrane potential at which the GABA puff was applied. More positive membrane potentials, by being farther from resting $E_{\mathrm{GABAA}}$, served to increase the driving force for $\mathrm{Cl}^{-}$across activated $\mathrm{GABA}_{\mathrm{A}}$ Rs. The test GABA puff was always applied at the same membrane potential and allowed $E_{\mathrm{GABAA}}$ and hence $\left[\mathrm{Cl}^{-}\right]_{\mathrm{i}}$ to be calculated (see Materials and Methods). Although $\mathrm{Cl}^{-}$influx elicited by puffing over the dendrites had an obvious effect on the size and direction of the current evoked by the test puff (Fig. 4B), a much reduced effect was seen when $\mathrm{Cl}^{-}$was loaded over the soma (Fig. 4C). Population data confirmed this difference (Fig. $4 D, E)$. The slope of the linear fit between $\mathrm{Cl}^{-}$load and change in $\left[\mathrm{Cl}^{-}\right]_{\mathrm{i}}$ was significantly steeper for $\mathrm{GABA}_{\mathrm{A}} \mathrm{R}$ currents elicited over the dendrites $(37.84 \pm 4.38 \mathrm{~mm} / \mathrm{nC})$ as opposed to the soma $(5.85 \pm 0.89 \mathrm{~mm} / \mathrm{nC} ; p<0.0001, t$ test; Fig. $4 D)$ in organotypic hippocampal slices. Similarly in acute slices, the slope of the lin- ear fit between $\mathrm{Cl}^{-}$load and change in $\left[\mathrm{Cl}^{-}\right]_{\mathrm{i}}$ was significantly steeper for the dendritic compartment $(72.20 \pm 10.46 \mathrm{~mm} / \mathrm{nC})$ compared with the somatic compartment (16.02 $\pm 1.040 \mathrm{~mm} /$ nC; $p<0.0001, t$ test; Fig. 4E). These data are consistent with the idea that the volume of the subcellular compartment affects the rate of $\mathrm{Cl}^{-}$accumulation. To confirm this, we simulated the effect of $\mathrm{Cl}^{-}$loads on $\left[\mathrm{Cl}^{-}\right]_{\mathrm{i}}$ changes using a singlecompartment cylindrical model of different volumes. For a given $\mathrm{Cl}^{-}$load, a smaller volume compartment resulted in larger increases in $\left[\mathrm{Cl}^{-}\right]_{\mathrm{i}}$ (Fig. $4 F$ ).

These observations support the conclusion that the dendritic compartment is generally more susceptible to $\mathrm{Cl}^{-}$loads than the somatic compartment. Therefore, the larger depolarizing shift in $E_{\text {GABAA }}$ observed at the soma during epileptiform activity cannot be accounted for by biophysical differences between these two compartments. Rather, it is consistent with previous evidence that somatic-targeting GABAergic inputs are relatively more active during epileptiform activity than their dendritic-targeting counterparts (Fujiwara-Tsukamoto et al., 2010).

GABAergic inputs from $\mathrm{PV}^{+}$interneurons become excitatory during epileptiform activity and can elicit $\mathrm{ADs}$ in pyramidal neurons

The large depolarizing shift in $E_{\mathrm{GABAA}}$ observed at the soma of pyramidal neurons suggests that somatic-targeting GABAergic 
A

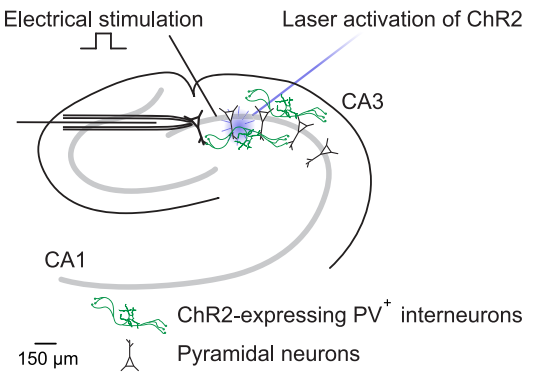

D

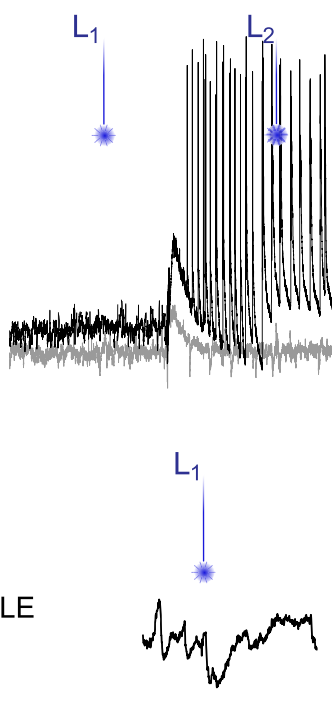

No SLE<smiles>CO[N+]([O-])(O)O[Na]</smiles>

E

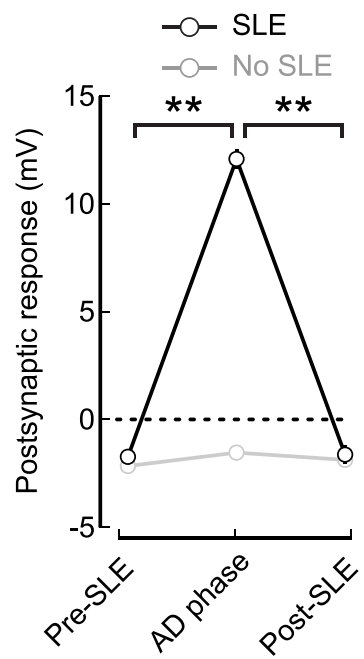

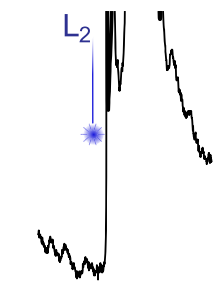

F

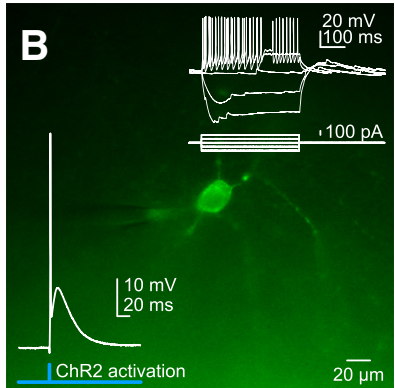

$\mathrm{L}_{3} \quad \mathrm{~L}_{4}$

- SLE

- No SLE

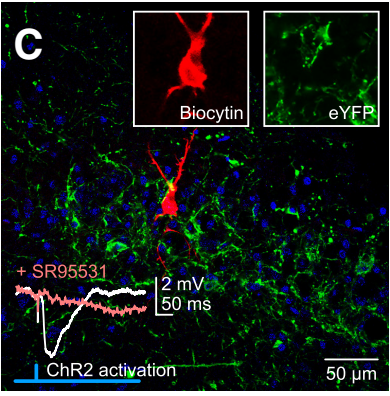

$\mathrm{L}_{5}$ $10 \mathrm{mV}$
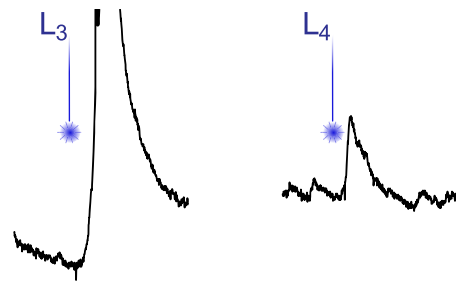

$\mathrm{L}_{5}$

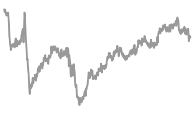

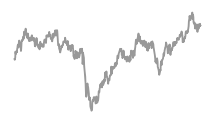

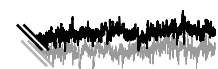<smiles>CC1(C)C2CCCC3C(C2)CC31C</smiles>

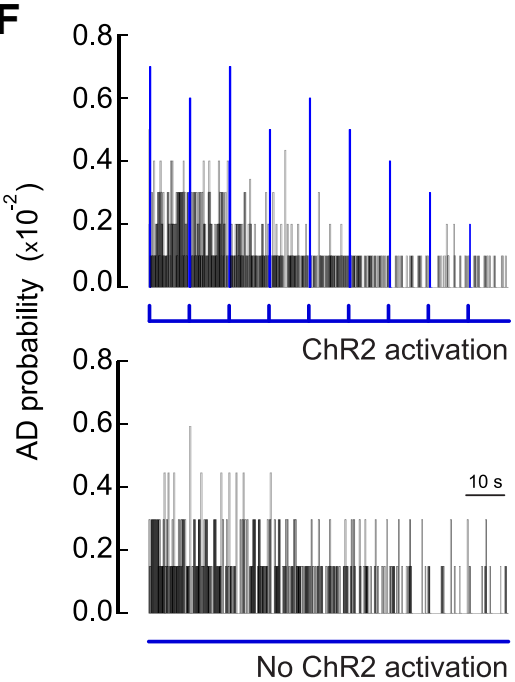

G

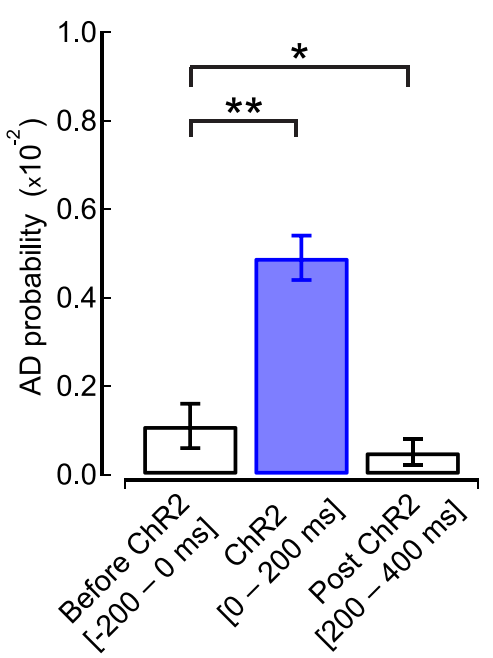

Figure 5. GABAergic inputs from $\mathrm{PV}^{+}$interneurons become excitatory during epileptiform activity and can elicit ADs in pyramidal neurons. $A$, The experimental setup consisted of a hippocampal slice containing PV ${ }^{+}$interneurons expressing ChR2-YFP. Individual CA3 pyramidal neurons were patched and epileptiform activity was initiated via a stimulating electrode placed in the pyramidal cell layer. $\boldsymbol{B}$, Recordings from the ChR2-YFP cells confirmed that they exhibit the characteristic I-V relationship and spiking activity of PV ${ }^{+}$fast spiking interneurons (top right) and that optical activation with blue laser pulses ( $473 \mathrm{~nm}, 1 \mathrm{~ms}$ duration) elicited action potentials in these cells (bottom left). C, Activating PV ${ }^{+}$ChR2-expressing interneurons elicited an IPSP in nearby CA3 pyramidal neurons (bottom left), which was blocked by application of a GABA R Rantagonist (SR95531, $200 \mathrm{~nm}$ ). Here the CA3 pyramidal neuron was filled with biocytin during recording and revealed post hoc using streptavidin- 405 (red). Note the restricted localization of YFP ${ }^{+}$fibers (green) in the pyramidal cell layer, as delineated by Nissl staining (blue). D, Representative recording (top) from a CA3 pyramidal neuron in which electrical stimulation led to the initiation of an SLE (black trace) and a control trial in which the stimulation intensity was reduced below the threshold for eliciting an SLE (gray trace). Every $10 \mathrm{~s}, \mathrm{PV}^{+}$ChR2-expressing interneurons were optically activated, and example postsynaptic responses (bottom) are shown for different time points $\left(\mathrm{L}_{1}-\mathrm{L}_{5}\right)$. Note the change in the postsynaptic response after activation of the $\mathrm{PV}^{+}$interneurons from a hyperpolarizing response in the pre-SLE period, to depolarizing and excitatory responses during the AD phase, and back to hyperpolarizing in the post-SLE period. E, The mean postsynaptic response after optical activation of $\mathrm{PV}^{+}$interneurons was depolarizing during the $\mathrm{AD}$ phase (Figure legend continues.) 
interneurons would be well placed to coordinate excitatory activity during the $\mathrm{AD}$ phase. To investigate this, we used an optogenetic approach to isolate and selectively activate $\mathrm{PV}^{+}$ interneurons during different phases of epileptiform activity. PV is expressed by a large proportion of somatic-targeting interneurons in the hippocampus, including basket cells and axo-axonic cells (Klausberger et al., 2003; Somogyi and Klausberger, 2005). To express ChR2-YFP in $\mathrm{PV}^{+}$interneurons, we used injections of AAV2 containing the double-floxed sequence for the light activatable channel ChR2-YFP in the ventral hippocampus of PVCre mice (Fig. 5A). After a survival time of $4-8$ weeks, which enabled sufficient expression of ChR2-YFP in the somata and axonal arbors of the $\mathrm{PV}^{+}$interneurons, transverse hippocampal slices were prepared. Fluorescence illumination revealed a dense network of YFP-positive fibers localized to stratum pyramidale and consistent with a perisomatic axonal projection pattern (Fig. $5 C)$. We found that short, $1 \mathrm{~ms}$ blue laser $(470 \mathrm{~nm})$ light pulses delivered to stratum pyramidale of the slice generated single action potentials in fast-spiking $\mathrm{YFP}^{+}$neurons (Fig. 5B). Conversely, whole-cell current-clamp recordings from postsynaptic CA3 pyramidal neurons showed pronounced IPSPs after blue laser light pulses $(1 \mathrm{~ms}, 470 \mathrm{~nm})$, which were mediated by $\mathrm{GABA}_{\mathrm{A}} \mathrm{Rs}$ because they could be blocked by bath application of the $\mathrm{GABA}_{\mathrm{A}} \mathrm{R}$ antagonist SR95531 (200 nM; $n=3$; Fig. 5C).

To investigate how the postsynaptic effects of $\mathrm{PV}^{+}$interneurons change during epileptiform activity, we elicited SLEs and optically activated $\mathrm{PV}^{+}$interneurons in stratum pyramidale (Fig. $5 A, D)$. SLEs were facilitated in acute slices by superfusion with aCSF containing $0 \mathrm{mM} \mathrm{Mg}^{2+}$ and $5 \mathrm{mM} \mathrm{K}^{+}$at a rate of $6 \mathrm{ml} / \mathrm{min}$ (Anderson et al., 1986; Mody et al., 1987; Gutiérrez et al., 1999). The onset of SLEs was controlled by delivering a brief train of electrical stimuli (20 pulses at $100 \mathrm{~Hz}$ ) via a stimulating electrode positioned in CA3 stratum pyramidale (Etherington and Frenguelli, 2004). Once the correct stimulation intensity was identified, SLEs could be elicited every $10 \mathrm{~min}$. Whole-cell patch-clamp recordings from CA3 pyramidal neurons (Fig. 5D) confirmed that the epileptiform activity exhibited an initial tonic component (characterized by a pronounced depolarization of the membrane potential), which again transitioned into a clonic phase characterized by a relatively hyperpolarized membrane potential with rhythmic high-amplitude bursts (ADs) that were hypersynchronous across the CA3 region (Fig. 6D). Optical activation of $\mathrm{PV}^{+}$interneurons (with $1 \mathrm{~ms}$ laser pulses every $10 \mathrm{~s}$ for the duration of the recording) enabled us to investigate the postsynaptic effects of $\mathrm{PV}^{+}$interneurons before, during, and after epileptiform activity. $\mathrm{PV}^{+}$interneuron-mediated PSPs were hyperpolarizing in the pre-SLE period but became robustly depolarizing during the AD phase (pre-SLE, $-1.73 \pm 0.35 \mathrm{mV}$; AD phase, $12.08 \pm 1.00 \mathrm{mV} ; p<0.01$, paired samples $t$ test; $n=26)$ and then returned to hyperpolarizing after the SLE (post-SLE, $-1.63 \pm$ $0.42 \mathrm{mV} ; p<0.01$, paired samples $t$ test; $n=26$; Fig. $5 D, E$ ). In control trials in which the stimulation intensity was below the

\section{$\leftarrow$}

(Figure legend continued.) but hyperpolarizing during the pre- and post-SLE periods $\left({ }^{* *} p<\right.$ $0.01, t$ test). $F$, Activation of PV ${ }^{+}$interneurons evokes ADs during the AD phase. Histogram (200 ms bin width) shows the $A D$ probability recorded when $\mathrm{PV}^{+}$interneurons were optically activated (top; blue bars) and when there was no laser activation of ChR2 (bottom). G, Optical activation of $\mathrm{PV}^{+}$interneurons entrains $\mathrm{AD}$ s and recruits endogenous $\mathrm{AD}$ mechanisms. Activation of $\mathrm{PV}^{+}$interneurons every 10 s caused an immediate fivefold increase in the probability of an $\mathrm{AD}\left(0-200\right.$ ms after activation; ${ }^{* *} p<0.01, t$ test), which was then followed by an immediate decrease in the probability of an $\mathrm{AD}\left(200-400 \mathrm{~ms}\right.$ after ChR2 activation; ${ }^{*} p<0.05, t$ test). threshold for eliciting epileptiform activity, $\mathrm{PV}^{+}$interneuronmediated PSPs remained hyperpolarizing throughout $(-2.16 \pm$ $0.24,-1.82 \pm 0.20$, and $-1.87 \pm 0.24 \mathrm{mV}$; corresponding to the pre-SLE period, AD phase, and post-SLE period, respectively; $n=23$; Fig. $5 D, E)$. Finally, in a subset of slices in which spontaneous epileptiform activity occurred without electrical stimulation, the $\mathrm{PV}^{+}$interneuron-mediated PSPs again became depolarizing during the $\mathrm{AD}$ phase (pre-SLE, $-0.5 \pm 0.1 \mathrm{mV} ; \mathrm{AD}$ phase, $10.1 \pm 0.6 \mathrm{mV}$; and post-SLE, $-0.2 \pm 0.04 \mathrm{mV} ; p<0.01$, paired samples $t$ test; $n=5$ ).

Not only did we observe that $\mathrm{PV}^{+}$interneuron-mediated PSPs became depolarizing during the epileptiform activity but also that ChR2 activation could induce ADs in the majority of cases (Fig. 5D). An analysis of the ADs revealed that optically activating $\mathrm{PV}^{+}$interneurons did not increase the mean $\mathrm{AD}$ frequency during SLEs (no ChR2 activation, $0.77 \pm 0.08 \mathrm{~Hz}$ compared with ChR2 activation, $0.80 \pm 0.05 \mathrm{~Hz} ; p>0.05$, independent-samples $t$ test; $n=10$ and $n=33$ ). However, $\mathrm{PV}^{+}$ interneuron activation generated a robust entrainment in the timing of ADs (Fig. $5 F$ ). Overall, the probability of an AD occurring was five times higher in the $200 \mathrm{~ms}$ immediately after $\mathrm{PV}^{+}$ interneuron activation (mean probability of $0.49 \pm 0.05 \times 10^{-2}$; $0-200 \mathrm{~ms}$ after ChR2 activation) than in the $200 \mathrm{~ms}$ preceding ChR2 activation (mean probability of $0.11 \pm 0.05 \times 10^{-2}$; $p<$ 0.01 , paired-samples $t$ test; $n=26$; Fig. $5 G$ ). Furthermore, consistent with the idea that optically evoked ADs recruited the same network mechanisms as endogenous ADs, the probability of an $\mathrm{AD}$ occurring dropped to $0.05 \pm 0.03 \times 10^{-2}$ in the period $200-400 \mathrm{~ms}$ after ChR2 activation, which was significantly lower than the probability before ChR2 activation $(p<0.05$, pairedsamples $t$ test; $n=26$; Fig. $5 G$ ).

In summary, selective activation of $\mathrm{PV}^{+}$interneurons generated IPSPs before the epileptiform activity, but these became strongly depolarizing by the clonic $\mathrm{AD}$ phase of the epileptiform activity. Moreover, the depolarization mediated by the $\mathrm{PV}^{+}$interneurons was sufficient to elicit and entrain clonic ADs in the hippocampal network.

\section{$\mathrm{PV}^{+}$interneurons recruit and synchronize excitation across distant pyramidal neurons during the $\mathrm{AD}$ phase}

Clonic ADs are large-amplitude events that recruit synchronous network activity across the tissue (Trevelyan et al., 2007a; Jiruska et al., 2013). To investigate the extent to which $\mathrm{PV}^{+}$interneurons can recruit synchronous network activity during the $\mathrm{AD}$ phase, we performed dual whole-cell patch-clamp recordings from a "local" and a "distal" pyramidal neuron in the CA3 region (Fig. $6 A, B)$. In the majority of cases, subsequent histological analysis enabled us to confirm the distance between the somata of the recorded neurons as $474 \pm 25 \mu \mathrm{m}$ ( $n=5$ pairs). First, and consistent with our observations in organotypic hippocampal slices (Fig. 1), our dual recordings in acute slices revealed that synchrony (as measured using linear correlation; see Materials and Methods) between pyramidal neurons increased during epileptiform activity (pre-SLE, $r=0.16 \pm 0.04$; tonic, $r=0.71 \pm 0.05$; $\mathrm{AD}, r=0.94 \pm 0.01$; and post-SLE, $r=0.13 \pm 0.05 ; n=17 \mathrm{SLEs}$ ) and reached its maximum during the $\mathrm{AD}$ phase (tonic vs $\mathrm{AD}$ phase; $p<0.01$, paired-samples $t$ test; $n=17$ SLEs; Fig. $6 C, D$ ). The high correlation value recorded during the $\mathrm{AD}$ phase was associated with an increase in the speed with which activity propagated through the network. Whereas the delay in the onset of the tonic phase recorded from the two neurons was calculated as $51.6 \pm 15.8 \mathrm{~ms}$, the onset of ADs exhibited a delay of only $3.96 \pm$ $0.95 \mathrm{~ms}$ ( $n=6$ pairs). Such an increase in propagation speed 
A

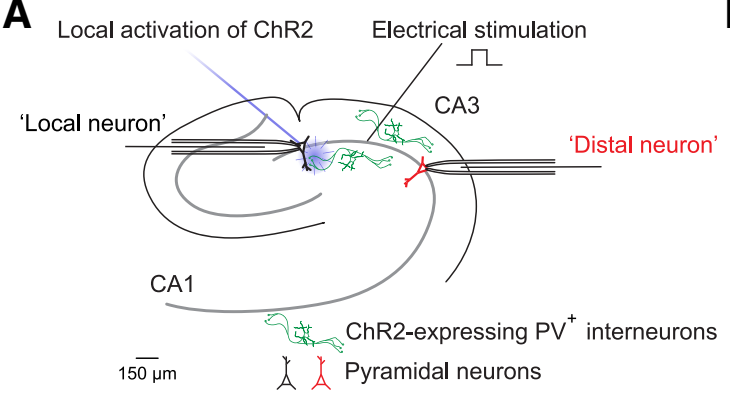

C

$t_{1} r=0.21$

$t_{2} r=0.68$
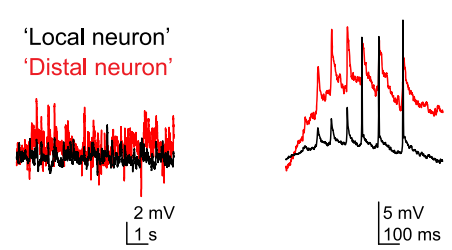

$\mathrm{L}_{1}$
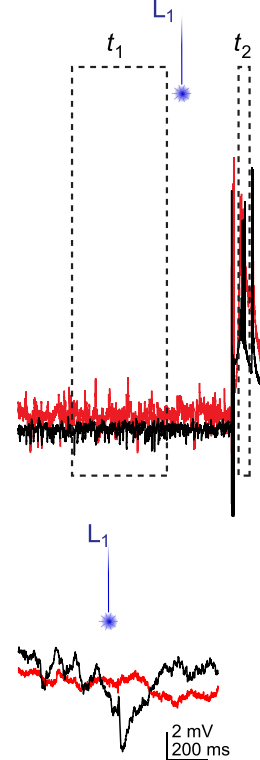

B

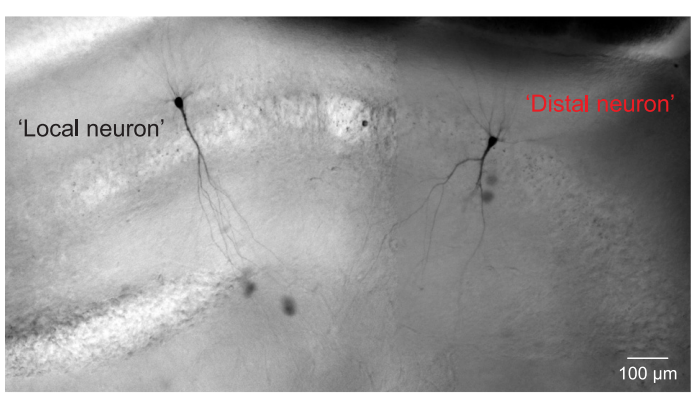

D
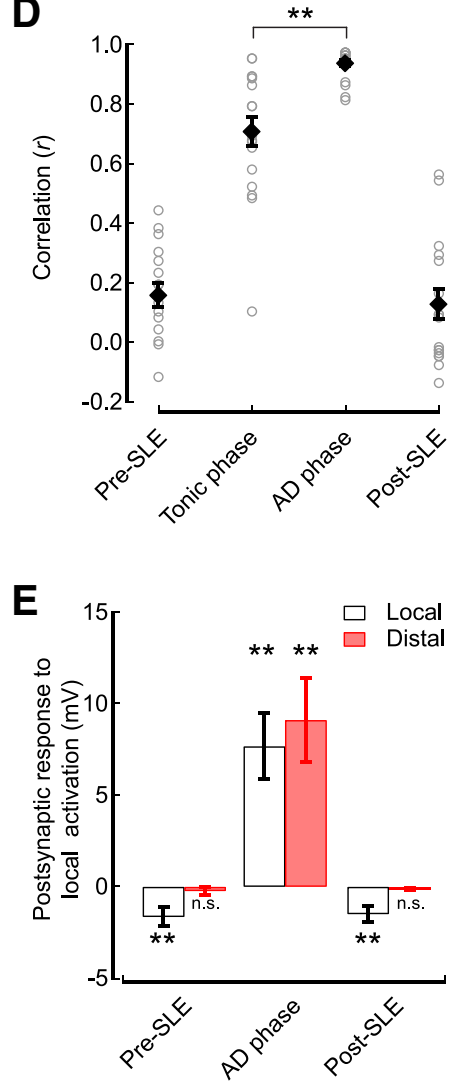

Figure 6. $\mathrm{PV}^{+}$interneuron activation can recruit and synchronize excitation across the CA3 region during the AD phase. $A$, In hippocampal slices containing PV ${ }^{+}$interneurons expressing ChR2-YFP, simultaneous recordings were made from two spatially separated pyramidal neurons at opposite ends of the CA3 region. Localized activation of PV ${ }^{+}$ChR2-expressing interneurons was only performed close to one of the pyramidal neurons, the local pyramidal neuron (black), by delivering spatially targeted blue laser pulses (40 $\mu \mathrm{m}$ spot size; see Materials and Methods). The pyramidal neuron that was distant to the region of ChR2 activation was referred to as the distal neuron (red). Epileptiform activity was initiated via a stimulating electrode placed equidistant between the pyramidal neurons. $\boldsymbol{B}$, Two representative neurons that were filled with biocytin during recording and subsequently reacted with DAB. $\boldsymbol{C}$, Membrane potential traces (middle) recorded simultaneously from a local (black) and a distal (red) CA3 pyramidal neuron. Four different epochs $\left(t_{1}-t_{4}\right)$ are denoted by dashed rectangles and were used to calculate the degree of correlated activity over the course of the SLE. Correlation coefficients were calculated across $8 \mathrm{~s}$ time windows, except for the tonic phase in which the entire phase was used (mean duration, $2.0 \pm 0.3 \mathrm{~s} ; n=$ 17).The corresponding expanded traces and Pearson's correlation coefficients are shown (top insets). The highest correlated activity occurred during the $A D$ phase $\left(t_{3}\right)(* * p<0.01, t$ test). Also indicated are three time points $\left(\mathrm{L}_{1}-\mathrm{L}_{3}\right.$, blue) at which $\mathrm{PV}^{+}$interneurons close to the local neuron were optically activated and for which the corresponding expanded traces are shown (bottom insets). Note that the distal neuron did not show a response to $\mathrm{PV}^{+}$interneuron activation in the pre-SLE $\left(\mathrm{L}_{1}\right)$ or post- $S L E\left(\mathrm{~L}_{3}\right)$ periods. However, activating the same $\mathrm{PV}{ }^{+}$interneurons during the $A D$ phase $\left(L_{2}\right)$ elicited an $A D$ in both the local and distal pyramidal neurons. $D$, Population data showing that the highest level of correlated activity between pairs of distant $C A 3$ pyramidal neurons occurred during the AD phase $\left({ }^{* *} p<0.01, t\right.$ test). $E$, Activation of $\mathrm{PV}{ }^{+}$interneurons during the AD phase recruits excitatory effects across the CA3 region. During the pre-SLE period, pyramidal neurons that are distal to the activated $\mathrm{PV}^{+}$interneurons did not show any postsynaptic response. However, activating the same $\mathrm{PV}^{+}$interneurons during the $\mathrm{AD}$ phase caused $\mathrm{ADs}$ that were evident in both the local and distal pyramidal neurons $\left({ }^{* *} p<0.01, t\right.$ test).

would be expected to contribute to the higher levels of correlated activity during the $\mathrm{AD}$ phase and supports the conclusion that specific circuit dynamics underlie this phase of epileptiform activity.

Next, we assessed whether local activation of a subset of $\mathrm{PV}^{+}$ interneurons could recruit a "full" $\mathrm{AD}$ across the CA3 region. $\mathrm{PV}^{+}$interneurons close to the local pyramidal neuron were activated using a small spot of blue laser light $(\sim 40 \mu$ m diameter; see
Materials and Methods), which under pre-SLE conditions evoked an IPSP in the local pyramidal neuron but no response in the distal pyramidal neuron (Fig. 6C,E). However, the same optical activation had different effects when delivered during SLEs. During the $\mathrm{AD}$ phase, optical activation of $\mathrm{PV}^{+}$interneurons close to the local pyramidal neuron now generated robust $\mathrm{AD}$ responses in both local pyramidal neurons and distal pyramidal neurons (AD phase local, $7.68 \pm 1.80 \mathrm{mV}$; and $\mathrm{AD}$ phase distal, 

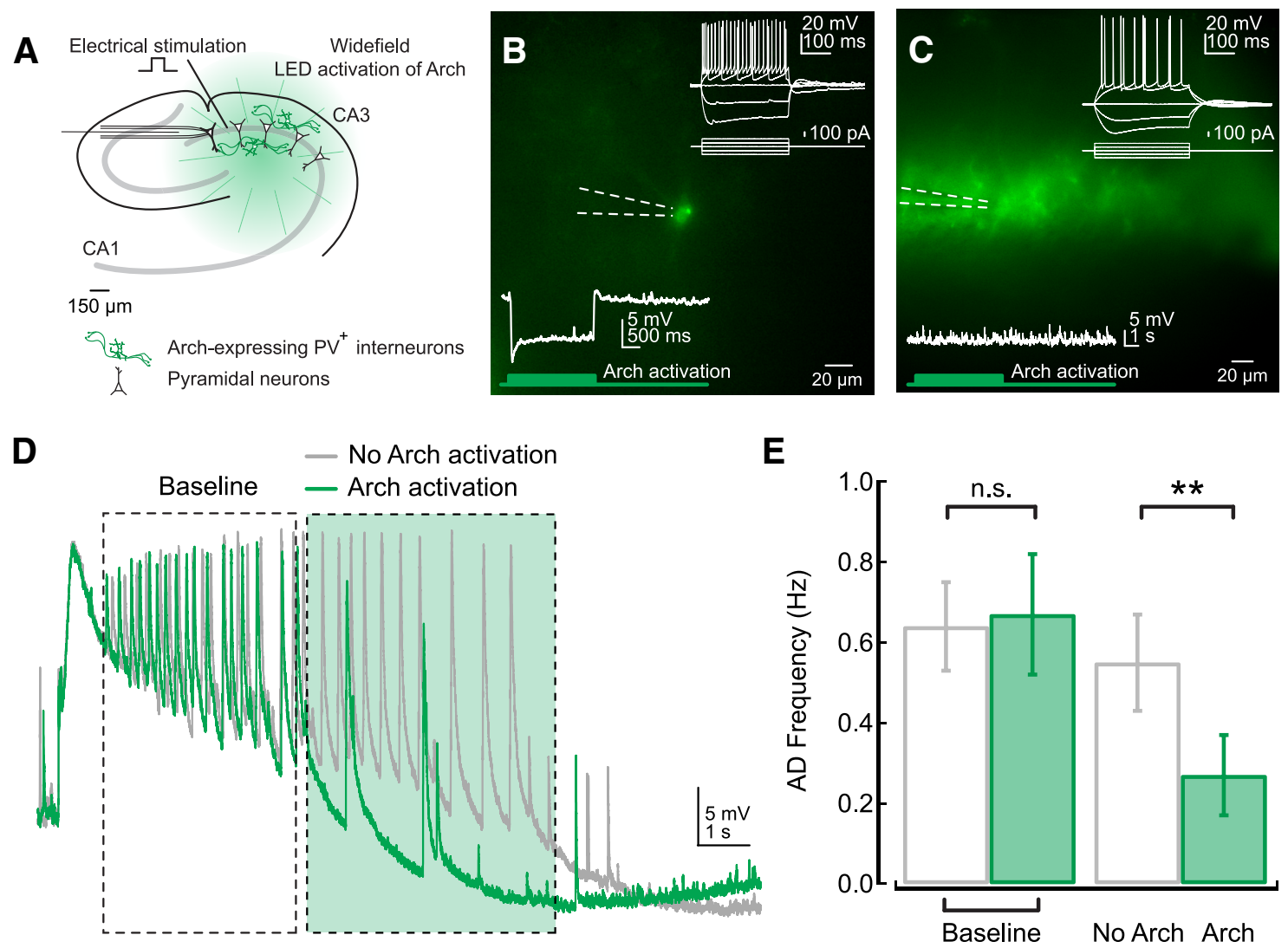

Figure 7. The frequency of ADs is reduced by optically silencing $\mathrm{PV}^{+}$interneurons. $A$, The experimental setup consisted of a hippocampal slice in which $\mathrm{PV}^{+}$interneurons throughout the $\mathrm{CA} 3$ region expressed Arch-GFP. Individual CA3 pyramidal neurons were targeted for whole-cell current-clamp recordings and epileptiform activity was induced via a stimulating electrode in the pyramidal cell layer. Arch was activated across the entire CA3 region using a wide-field green LED (530 nm). B, Recordings from the Arch-expressing neurons confirmed that they exhibit the characteristic $/-V$ relationship and spiking activity of $\mathrm{PV}^{+}$fast spiking interneurons (top right) and that activating Arch resulted in a sustained hyperpolarization of the membrane potential (bottom left). $C$, Inhibition with Arch was specific to $\mathrm{PV}^{+}$interneurons. Recordings from pyramidal neurons (confirmed from firing pattern; top right) showed no response during Arch activation under resting conditions (bottom left). D, Representative recording of two consecutive SLEs from a CA3 pyramidal neuron. In the control SLE (gray trace), there was no Arch activation. In the other SLE (green trace), $\mathrm{PV}^{+}$interneurons were selectively inhibited during the AD phase by activating Arch (highlighted green region). This resulted in a marked reduction in the incidence of ADs. $E$, Population data showing a significant reduction in $\mathrm{AD}$ frequency during optical inhibition of $\mathrm{PV}^{+}$interneurons ( ${ }^{* *} p<0.01, t$ test).

$9.12 \pm 2.28 \mathrm{mV} ; n=7$; Fig. $6 C, E)$. Thus, $\mathrm{PV}^{+}$interneurons exhibited an extended sphere of influence during the $\mathrm{AD}$ phase that mediated synchronous excitation across pyramidal neurons. Importantly, when we compared endogenous ADs with those that were evoked via optical activation of local $\mathrm{PV}^{+}$interneurons, we found that the ADs were very similar in terms of their spatiotemporal properties. The delay in $\mathrm{AD}$ onset and degree of synchronization between the local and distal pyramidal neurons was not different for endogenous ADs (time delay, $3.96 \pm 0.95 \mathrm{~ms}$; Pearson's correlation, $r=0.92 \pm 0.04$ ) and optically evoked ADs (time delay, $3.10 \pm 0.82 \mathrm{~ms}$; Pearson's correlation, $r=0.92 \pm$ $0.03 ; p>0.05$ in both cases, independent-samples $t$ test; $n=6$ ). Together, these results reveal that $\mathrm{PV}^{+}$interneurons are well placed to synchronize ADs across large assemblies of pyramidal neurons in the $\mathrm{CA} 3$ region.

\section{Inhibiting $\mathrm{PV}^{+}$interneurons during epileptiform activity reduces $\mathrm{AD}$ incidence}

The fact that selectively activating $\mathrm{PV}^{+}$interneurons can entrain $\mathrm{ADs}$, which appear to recruit the same network mechanisms as endogenous ADs, suggests that the excitatory postsynaptic effects of $\mathrm{PV}^{+}$interneurons are a critical component of ADs. To test this directly, we set out to silence $\mathrm{PV}^{+}$interneurons during the $\mathrm{AD}$ phase and thereby assess whether $\mathrm{PV}^{+}$interneurons are necessary for maintaining ADs. Injections of AAV2 containing the double-floxed sequence for the light activatable $\mathrm{H}^{+}$pump Arch were made into the ventral hippocampus of PV-Cre mice to express Arch-GFP in $\mathrm{PV}^{+}$interneurons. This enabled a selective hyperpolarization of $\mathrm{PV}^{+}$interneurons by up to $20 \mathrm{mV}$ (mean of $-8.9 \pm 4.3 \mathrm{mV} ; n=4$; Fig. $7 B, C$ ) in acute hippocampal brain slices prepared 4-8 weeks later. To test the contribution of $\mathrm{PV}^{+}$ interneurons during the $\mathrm{AD}$ phase, we selected slices that exhibited strong somatic expression of Arch-GFP throughout the CA3 region and activated Arch across this area of the slice with a wide-field green light-emitting diode $(530 \mathrm{~nm}$; see Materials and Methods; Fig. 7A). SLEs were initiated and monitored as described previously, and a within-slice design was used to compare SLEs in which the activity of $\mathrm{PV}^{+}$interneurons was left undisturbed or in which $\mathrm{PV}^{+}$interneurons were inhibited for a period of $10 \mathrm{~s}$ during the $\mathrm{AD}$ phase (Fig. $7 A, D$ ). The order in which SLEs were paired with optical activation of Arch was randomized. Optical silencing of $\mathrm{PV}^{+}$interneurons during the $\mathrm{AD}$ phase caused a significant decrease in the frequency of ADs (Fig. $7 D, E$ ). $\mathrm{AD}$ frequency without Arch activation was $0.55 \pm 0.12 \mathrm{~Hz}$, whereas $\mathrm{AD}$ frequency during Arch activation dropped to $0.27 \pm 0.10 \mathrm{~Hz}$ $(p<0.01$, paired Student's $t$ test; $n=8$; Fig. $7 E)$. Together, these results are consistent with the conclusion that the excitatory effects of $\mathrm{PV}^{+}$interneurons serve to maintain epileptiform activity by recruiting synchronous ADs. 


\section{Discussion}

Here we have used in vitro hippocampal slice models of epileptiform activity to investigate the mechanisms that contribute to hypersynchronous ADs during the clonic phase of seizures. Our data show that the generation of $\mathrm{ADs}$ in the $\mathrm{CA} 3$ region requires GABAergic transmission that becomes excitatory as a result of a transient collapse in $E_{\mathrm{GABAA}}$. The resulting depolarizing shift in GABAergic signaling is most pronounced at the somatic region of pyramidal neurons, and release of GABA from perisomatictargeting $\mathrm{PV}^{+}$interneurons during the clonic phase can entrain ADs that recruit pyramidal neurons across the network. Meanwhile, selective inhibition of $\mathrm{PV}^{+}$interneurons during the clonic phase has the inverse effect and causes a reduction in the frequency of ADs. Together, these results demonstrate that, once epileptiform activity is established, $\mathrm{PV}^{+}$interneurons are able to maintain epileptiform activity dynamics through direct depolarizing effects on their postsynaptic targets.

States of hypersynchrony have been induced classically by enabling recurrently connected excitatory neurons to synchronize their activity via removal of feedforward and feedback synaptic inhibition (Miles and Wong, 1983, 1987). We find that the hypersynchronous clonic $A D$ phase is dependent on $G_{A B A} R$ mediated transmission, because blocking $\mathrm{GABA}_{\mathrm{A}} \mathrm{R}$ activity markedly reduces the occurrence of ADs. This is consistent with the observation that ADs after tetanic stimulation of CA1 "minislices" can be blocked by application of the GABA ${ }_{A} R$ antagonist bicuculline (Fujiwara-Tsukamoto et al., 2003; Isomura et al., 2003) and reports that AD-like activity can be generated in the absence of glutamatergic transmission (Fujiwara-Tsukamoto et al., 2010). Our results extend these previous observations and are consistent with GABA and interneuronal networks playing a key role in the clonic $\mathrm{AD}$ phase of epileptic seizures.

The fact that $\mathrm{GABA}_{\mathrm{A}} \mathrm{R}$ signaling becomes excitatory during the $\mathrm{AD}$ phase of four different in vitro models of hippocampal epileptiform activity strongly suggests that this is a general feature of epileptiform activity. Using gramicidin perforated patchclamp recordings, we confirmed that this was attributable to a epileptiform-associated depolarizing shift in $E_{\mathrm{GABAA}}$, which is likely to result from the loading of $\mathrm{Cl}^{-}$through $\mathrm{GABA}_{\mathrm{A}} \mathrm{Rs}$ (Fujiwara-Tsukamoto et al., 2007; Isomura et al., 2008; Ilie et al., 2012, Raimondo et al., 2013), although modulation of potassium-chloride-cotransporter proteins may also contribute (DeFazio et al., 2000; Viitanen et al., 2010). Indeed, the intense activation of $\mathrm{GABA}_{\mathrm{A}} \mathrm{Rs}$ and concurrent membrane depolarization that occurs during seizures provides the ideal conditions for rapid intracellular $\mathrm{Cl}^{-}$accumulation (Raimondo et al., 2012). By probing $\mathrm{GABA}_{\mathrm{A}} \mathrm{R}$ responses in both the dendritic and somatic compartments of pyramidal neurons, we found that, although both compartments undergo a depolarizing shift in $E_{\mathrm{GABAA}}$, the effect is most pronounced at the soma and cannot be accounted for by space-clamp effects associated with somatic voltage-clamp recordings. In agreement with previous observations (Staley and Proctor, 1999), we show that the smaller-volume dendritic compartment is more susceptible to changes in intracellular $\mathrm{Cl}^{-}$ concentration. Furthermore, one might expect enhanced $\mathrm{Cl}^{-}$ accumulation within dendrites because they are the predominant site of depolarizing glutamatergic drive, and the relative amplitude of GABAergic PSPs to dendrites can increase when recurrent inhibitory circuits are repeatedly activated (Pouille and Scanziani, 2004). In addition, perisomatic synapses formed by $\mathrm{PV}^{+}$ interneurons are regulated by voltage-dependent $\mathrm{Cl}^{-}$channels that serve to reduce intracellular $\mathrm{Cl}^{-}$accumulation (Földy et al.,
2010). Therefore, our observations suggest that $\mathrm{GABA}_{\mathrm{A}} \mathrm{Rs}$ at the soma must be considerably more active than dendritic $\mathrm{GABA}_{\mathrm{A}} \mathrm{Rs}$ during the early phase of SLE activity. This is supported by evidence that somatic-targeting, fast-spiking interneurons are most strongly recruited around SLE onset (Timofeev et al., 2002; Ziburkus et al., 2006; Gnatkovsky et al., 2008; Fujiwara-Tsukamoto et al., 2010; Cammarota et al., 2013).

Optogenetic techniques enabled us to dissect how epileptiform-associated changes in $E_{\mathrm{GABAA}}$ influence the effect of somatic-targeting interneurons on pyramidal neuron activity. We selectively activated or inhibited $\mathrm{PV}^{+}$interneurons, which comprise a large proportion of perisomatic-targeting interneurons, including basket cells and axo-axonic cells (Somogyi and Klausberger, 2005). As expected, ChR2-mediated optical activation of $\mathrm{PV}^{+}$interneurons before an SLE led to hyperpolarizing postsynaptic $\mathrm{GABA}_{\mathrm{A}} \mathrm{R}$ responses in $\mathrm{CA} 3$ pyramidal neurons. However, during SLEs, the postsynaptic $\mathrm{GABA}_{\mathrm{A}} \mathrm{R}$ responses rapidly became depolarizing, consistent with an activity-dependent depolarizing shift in $E_{\mathrm{GABAA}}$. On this background of excitatory GABAergic signaling, activation of $\mathrm{PV}^{+}$interneurons during the clonic phase was sufficient to directly initiate and entrain clonic $\mathrm{ADs}$ in pyramidal neurons of the CA3 region, such that the highest probability of $\mathrm{AD}$ generation occurred immediately after $\mathrm{PV}^{+}$interneuron activation. Additional evidence that somatictargeting interneurons are well placed to synchronize network excitation came from the fact that activating only a subset of $\mathrm{PV}^{+}$ interneurons during the clonic phase was able to drive synchronous excitation across distal regions of the network. This spatial feature of the excitatory actions of $\mathrm{PV}^{+}$interneurons suggests that the recruitment of an $\mathrm{AD}$ involves excitation through polysynaptic circuits or additional mechanisms, such as altered gapjunction synchronization during the clonic phase (Rouach et al., 2003; Beaumont and Maccaferri, 2011). Given the timing of AD propagation that we observed, it is possible that both of these mechanisms could contribute (Köhling et al., 2001). Importantly, the fact that the spatiotemporal properties of optically evoked $\mathrm{ADs}$ were indistinguishable from those of endogenous ADs suggests that they use the same underlying mechanisms and support the conclusion that somatic-targeting interneurons switch from restraining to perpetuating seizure activity. Finally, as a confirmation that $\mathrm{PV}^{+}$interneurons are involved in maintaining ADs, we demonstrated that widespread optical inhibition of $\mathrm{PV}^{+}$interneurons during the clonic phase significantly reduces $\mathrm{AD}$ frequency.

Previous work has focused on the onset of the tonic phase of seizures and how a network may generate, or succumb to, an ictal event. The onset of the tonic phase has been characterized as a transient breakdown of inhibitory synaptic mechanisms, which are normally recruited to "restrain" network excitability (Trevelyan et al., 2006, 2007b; Cammarota et al., 2013). Strong recruitment of GABAergic interneurons can lead to a temporary loss of this inhibitory restraint, via mechanisms such as a transient decrease in GABA release (Zhang et al., 2012), a reduction in postsynaptic $\mathrm{GABA}_{\mathrm{A}} \mathrm{R}$ inhibition (Lillis et al., 2012), or as a result of GABAergic interneurons entering a temporary state of depolarizing block (Ziburkus et al., 2006; Cammarota et al., 2013). Consistent with these ideas, it has been shown that interneurons are strongly recruited before the onset of an ictal event (Timofeev et al., 2002; Ziburkus et al., 2006; Fujiwara-Tsukamoto et al., 2010; Cammarota et al., 2013) and that modulating the activity of interneurons can disrupt the onset or propagation of seizure activity (Krook-Magnuson et al., 2013; Ledri et al., 2014). Our results extend these previous findings and support the view that dy- 
namic network and ionic mechanisms underlie the different phases of seizure activity (Krishnan and Bazhenov, 2011). This has implications for efforts to disrupt epileptic seizure activity and the design of intervention strategies that could respond to the dynamic nature of seizing circuits. The benefits of manipulating interneuron populations may differ depending on the timing of the manipulation relative to the seizure phase and seizure type, as well as the duration of the manipulation and the intrinsic properties of specific cell types that are targeted (Ziburkus et al., 2006; Cammarota et al., 2013). Our results also provide support for research into anticonvulsant therapies that aim to enhance the $\mathrm{Cl}^{-}$extrusion capacity of neurons (Gagnon et al., 2013), particularly in the context of status epilepticus in which the transient collapse in $E_{\mathrm{GABAA}}$ and transmembrane $\mathrm{Cl}^{-}$gradient is likely to be pronounced.

The ability of perisomatic-targeting interneurons to entrain hippocampal network activity through an inhibitory action of GABA has been well reported (Michelson and Wong, 1991; Cobb et al., 1995; Aradi and Maccaferri, 2004; Mann et al., 2005; Zsiros et al., 2007; Ellender et al., 2010). Early in development, when GABA is predominantly depolarizing (Ben-Ari, 2002), perisomatictargeting interneurons have been suggested to initiate hippocampal network activity through a direct depolarizing effect (Bonifazi et al., 2009; Picardo et al., 2011). We now show that perisomatictargeting interneurons can also have a direct excitatory and synchronizing effect in mature tissue, most likely by working in concert with an excitatory glutamatergic drive (de la Prida et al., 2006). Interestingly, multiple studies have shown an increase in structural and functional somatic inhibition in chronic epileptic conditions (Cossart et al., 2001; Wittner et al., 2001, 2005), which is likely to reflect a "protective response." However, such changes may represent a double-edged sword: although they may help reduce the initial likelihood of an epileptic event being generated, once GABAergic signaling is subverted and begins to exhibit excitatory effects, somatic-targeting GABAergic inputs may exacerbate ongoing seizure activity to an even greater extent.

\section{References}

Anderson WW, Lewis DV, Swartzwelder HS, Wilson WA (1986) Magnesium-free medium activates seizure-like events in the rat hippocampal slice. Brain Res 398:215-219. CrossRef Medline

Aradi I, Maccaferri G (2004) Cell type-specific synaptic dynamics of synchronized bursting in the juvenile CA3 rat hippocampus. J Neurosci 24: 9681-9692. CrossRef Medline

Ascoli GA (2006) Mobilizing the base of neuroscience data: the case of neuronal morphologies. Nat Rev Neurosci 7:318-324. CrossRef Medline

Avoli M, D’Antuono M, Louvel J, Köhling R, Biagini G, Pumain R, D'Arcangelo G, Tancredi V (2002) Network and pharmacological mechanisms leading to epileptiform synchronization in the limbic system in vitro. Prog Neurobiol 68:167-207. CrossRef Medline

Beaumont M, Maccaferri G (2011) Is connexin36 critical for GABAergic hypersynchronization in the hippocampus? J Physiol 589:1663-1680. CrossRef Medline

Ben-Ari Y (2002) Excitatory actions of gaba during development: the nature of the nurture. Nat Rev Neurosci 3:728-739. CrossRef Medline

Berdichevsky Y, Dzhala V, Mail M, Staley KJ (2012) Interictal spikes, seizures and ictal cell death are not necessary for post-traumatic epileptogenesis in vitro. Neurobiol Dis 45:774-785. CrossRef Medline

Bonifazi P, Goldin M, Picardo MA, Jorquera I, Cattani A, Bianconi G, Represa A, Ben-Ari Y, Cossart R (2009) GABAergic hub neurons orchestrate synchrony in developing hippocampal networks. Science 326:1419-1424. CrossRef Medline

Cammarota M, Losi G, Chiavegato A, Zonta M, Carmignoto G (2013) Fast spiking interneuron control of seizure propagation in a cortical slice model of focal epilepsy. J Physiol 591:807-822. CrossRef Medline

Carnevale NT, Hines ML (2006) The NEURON book. Cambridge, UK: Cambridge UP.
Chamberlin NL, Dingledine R (1988) GABAergic inhibition and the induction of spontaneous epileptiform activity by low chloride and high potassium in the hippocampal slice. Brain Res 445:12-18. CrossRef Medline

Chow BY, Han X, Dobry AS, Qian X, Chuong AS, Li M, Henninger MA, Belfort GM, Lin Y, Monahan PE, Boyden ES (2010) High-performance genetically targetable optical neural silencing by light-driven proton pumps. Nature 463:98-102. CrossRef Medline

Cobb SR, Buhl EH, Halasy K, Paulsen O, Somogyi P (1995) Synchronization of neuronal activity in hippocampus by individual GABAergic interneurons. Nature 378:75-78. CrossRef Medline

Cossart R, Dinocourt C, Hirsch JC, Merchan-Perez A, De Felipe J, Ben-Ari Y, Esclapez M, Bernard C (2001) Dendritic but not somatic GABAergic inhibition is decreased in experimental epilepsy. Nat Neurosci 4:52-62. CrossRef Medline

DeFazio RA, Keros S, Quick MW, Hablitz JJ (2000) Potassium-coupled chloride cotransport controls intracellular chloride in rat neocortical pyramidal neurons. J Neurosci 20:8069-8076. Medline

de la Prida LM, Huberfeld G, Cohen I, Miles R (2006) Threshold behavior in the initiation of hippocampal population bursts. Neuron 49:131-142. CrossRef Medline

Dyhrfjeld-Johnsen J, Berdichevsky Y, Swiercz W, Sabolek H, Staley KJ (2010) Interictal spikes precede ictal discharges in an organotypic hippocampal slice culture model of epileptogenesis. J Clin Neurophysiol 27:418-424. CrossRef Medline

Ellender TJ, Nissen W, Colgin LL, Mann EO, Paulsen O (2010) Priming of hippocampal population bursts by individual perisomatic-targeting interneurons. J Neurosci 30:5979-5991. CrossRef Medline

Etherington LA, Frenguelli BG (2004) Endogenous adenosine modulates epileptiform activity in rat hippocampus in a receptor subtype-dependent manner. Eur J Neurosci 19:2539-2550. CrossRef Medline

Földy C, Lee SH, Morgan RJ, Soltesz I (2010) Regulation of fast-spiking basket cell synapses by the chloride channel ClC-2. Nat Neurosci 13:10471049. CrossRef Medline

Fujiwara-Tsukamoto Y, Isomura Y, Nambu A, Takada M (2003) Excitatory GABA input directly drives seizure-like rhythmic synchronization in mature hippocampal CA1 pyramidal cells. Neuroscience 119:265-275. CrossRef Medline

Fujiwara-Tsukamoto Y, Isomura Y, Takada M (2006) Comparable GABAergic mechanisms of hippocampal seizurelike activity in posttetanic and low-Mg2 + conditions. J Neurophysiol 95:2013-2019. CrossRef Medline

Fujiwara-Tsukamoto Y, Isomura Y, Imanishi M, Fukai T, Takada M (2007) Distinct types of ionic modulation of GABA actions in pyramidal cells and interneurons during electrical induction of hippocampal seizure-like network activity. Eur J Neurosci 25:2713-2725. CrossRef Medline

Fujiwara-Tsukamoto Y, Isomura $\mathrm{Y}$, Imanishi M, Ninomiya T, Tsukada M, Yanagawa Y, Fukai T, Takada M (2010) Prototypic seizure activity driven by mature hippocampal fast-spiking interneurons. J Neurosci 30: 13679-13689. CrossRef Medline

Gagnon M, Bergeron MJ, Lavertu G, Castonguay A, Tripathy S, Bonin RP, Perez-Sanchez J, Boudreau D, Wang B, Dumas L, Valade I, Bachand K, Jacob-Wagner M, Tardif C, Kianicka I, Isenring P, Attardo G, Coull JA, De Koninck Y (2013) Chloride extrusion enhancers as novel therapeutics for neurological diseases. Nat Med 19:1524-1528. CrossRef Medline

Gnatkovsky V, Librizzi L, Trombin F, de Curtis M (2008) Fast activity at seizure onset is mediated by inhibitory circuits in the entorhinal cortex in vitro. Ann Neurol 64:674-686. CrossRef Medline

Gutiérrez R, Armand V, Schuchmann S, Heinemann U (1999) Epileptiform activity induced by low $\mathrm{Mg} 2+$ in cultured rat hippocampal slices. Brain Res 815:294-303. CrossRef Medline

Hájos N, Ellender TJ, Zemankovics R, Mann EO, Exley R, Cragg SJ, Freund TF, Paulsen O (2009) Maintaining network activity in submerged hippocampal slices: importance of oxygen supply. Eur J Neurosci 29:319327. CrossRef Medline

Higashima M, Kinoshita H, Yamaguchi N, Koshino Y (1996) Activation of GABAergic function necessary for afterdischarge generation in rat hippocampal slices. Neurosci Lett 207:101-104. CrossRef Medline

Ilie A, Raimondo JV, Akerman CJ (2012) Adenosine release during seizures attenuates GABAA receptor-mediated depolarization. J Neurosci 32: 5321-5332. CrossRef Medline

Isomura Y, Sugimoto M, Fujiwara-Tsukamoto Y, Yamamoto-Muraki S, Yamada J, Fukuda A (2003) Synaptically activated $\mathrm{Cl}^{-}$accumulation 
responsible for depolarizing GABAergic responses in mature hippocampal neurons. J Neurophysiol 90:2752-2756. CrossRef Medline

Isomura Y, Fujiwara-Tsukamoto Y, Takada M (2008) A network mechanism underlying hippocampal seizure-like synchronous oscillations. Neurosci Res 61:227-233. CrossRef Medline

Jiruska P, de Curtis M, Jefferys JG, Schevon CA, Schiff SJ, Schindler K (2013) Synchronization and desynchronization in epilepsy: controversies and hypotheses. J Physiol 591:787-797. CrossRef Medline

Kaila K, Lamsa K, Smirnov S, Taira T, Voipio J (1997) Long-lasting GABAmediated depolarization evoked by high-frequency stimulation in pyramidal neurons of rat hippocampal slice is attributable to a network-driven, bicarbonate-dependent $\mathrm{K}^{+}$transient. J Neurosci 17:7662-7672. Medline

Klausberger T, Somogyi P (2008) Neuronal diversity and temporal dynamics: the unity of hippocampal circuit operations. Science 321:53-57. CrossRef Medline

Klausberger T, Magill PJ, Márton LF, Roberts JD, Cobden PM, Buzsáki G, Somogyi P (2003) Brain-state- and cell-type-specific firing of hippocampal interneurons in vivo. Nature 421:844-848. CrossRef Medline

Köhling R, Gladwell SJ, Bracci E, Vreugdenhil M, Jefferys JG (2001) Prolonged epileptiform bursting induced by $0-\mathrm{Mg}(2+)$ in rat hippocampal slices depends on gap junctional coupling. Neuroscience 105:579-587. CrossRef Medline

Kramer MA, Truccolo W, Eden UT, Lepage KQ, Hochberg LR, Eskandar EN, Madsen JR, Lee JW, Maheshwari A, Halgren E, Chu CJ, Cash SS (2012) Human seizures self-terminate across spatial scales via a critical transition. Proc Natl Acad Sci U S A 109:21116-21121. CrossRef Medline

Krishnan GP, Bazhenov M (2011) Ionic dynamics mediate spontaneous termination of seizures and postictal depression state. J Neurosci 31:88708882. CrossRef Medline

Krook-Magnuson E, Armstrong C, Oijala M, Soltesz I (2013) On-demand optogenetic control of spontaneous seizures in temporal lobe epilepsy. Nat Commun 4:1376. CrossRef Medline

Kyrozis A, Reichling DB (1995) Perforated-patch recording with gramicidin avoids artifactual changes in intracellular chloride concentration. J Neurosci Methods 57:27-35. CrossRef Medline

Ledri M, Madsen MG, Nikitidou L, Kirik D, Kokaia M (2014) Global optogenetic activation of inhibitory interneurons during epileptiform activity. J Neurosci 34:3364-3377. CrossRef Medline

Lillis KP, Kramer MA, Mertz J, Staley KJ, White JA (2012) Pyramidal cells accumulate chloride at seizure onset. Neurobiol Dis 47:358-366. CrossRef Medline

Mann EO, Suckling JM, Hajos N, Greenfield SA, Paulsen O (2005) Perisomatic feedback inhibition underlies cholinergically induced fast network oscillations in the rat hippocampus in vitro. Neuron 45:105-117. CrossRef Medline

McCormick DA, Contreras D (2001) On the cellular and network bases of epileptic seizures. Annu Rev Physiol 63:815-846. CrossRef Medline

Michelson HB, Wong RK (1991) Excitatory synaptic responses mediated by GABAA receptors in the hippocampus. Science 253:1420-1423. CrossRef Medline

Miles R, Wong RK (1983) Single neurones can initiate synchronized population discharge in the hippocampus. Nature 306:371-373. CrossRef Medline

Miles R, Wong RK (1987) Inhibitory control of local excitatory circuits in the guinea-pig hippocampus. J Physiol 388:611-629. Medline

Mody I, Lambert JD, Heinemann U (1987) Low extracellular magnesium induces epileptiform activity and spreading depression in rat hippocampal slices. J Neurophysiol 57:869-888. Medline

Perreault P, Avoli M (1992) 4-aminopyridine-induced epileptiform activity and a GABA-mediated long-lasting depolarization in the rat hippocampus. J Neurosci 12:104-115. Medline

Picardo MA, Guigue P, Bonifazi P, Batista-Brito R, Allene C, Ribas A, Fishell G, Baude A, Cossart R (2011) Pioneer GABA cells comprise a subpopulation of hub neurons in the developing hippocampus. Neuron 71:695709. CrossRef Medline

Pouille F, Scanziani M (2004) Routing of spike series by dynamic circuits in the hippocampus. Nature 429:717-723. CrossRef Medline

Raimondo JV, Markram H, Akerman CJ (2012) Short-term ionic plasticity at GABAergic synapses. Front Synaptic Neurosci 4:5. CrossRef Medline

Raimondo JV, Joyce B, Kay L, Schlagheck T, Newey SE, Srinivas S, Akerman CJ (2013) A genetically-encoded chloride and $\mathrm{pH}$ sensor for dissociating ion dynamics in the nervous system. Front Cell Neurosci 7:202. CrossRef Medline

Rouach N, Segal M, Koulakoff A, Giaume C, Avignone E (2003) Carbenoxolone blockade of neuronal network activity in culture is not mediated by an action on gap junctions. J Physiol 553:729-745. CrossRef Medline

Schevon CA, Weiss SA, McKhann G Jr, Goodman RR, Yuste R, Emerson RG, Trevelyan AJ (2012) Evidence of an inhibitory restraint of seizure activity in humans. Nat Commun 3:1060. CrossRef Medline

Schindler K, Leung H, Elger CE, Lehnertz K (2007) Assessing seizure dynamics by analysing the correlation structure of multichannel intracranial EEG. Brain 130:65-77. CrossRef Medline

Scorza CA, Araujo BH, Leite LA, Torres LB, Otalora LF, Oliveira MS, Garrido-Sanabria ER, Cavalheiro EA (2011) Morphological and electrophysiological properties of pyramidal-like neurons in the stratum oriens of Cornu ammonis 1 and Cornu ammonis 2 area of Proechimys. Neuroscience 177:252-268. CrossRef Medline

Somogyi P, Klausberger T (2005) Defined types of cortical interneurone structure space and spike timing in the hippocampus. J Physiol 562:9-26. CrossRef Medline

Staley KJ, Proctor WR (1999) Modulation of mammalian dendritic GABA(A) receptor function by the kinetics of $\mathrm{Cl}^{-}$and $\mathrm{HCO}^{-}$transport. J Physiol 519:693-712. CrossRef Medline

Staley KJ, Soldo BL, Proctor WR (1995) Ionic mechanisms of neuronal excitation by inhibitory GABAA receptors. Science 269:977-981. CrossRef Medline

Stoppini L, Buchs PA, Muller D (1991) A simple method for organotypic cultures of nervous tissue. J Neurosci Methods 37:173-182. CrossRef Medline

Thompson SM, Gähwiler BH (1989) Activity-dependent disinhibition. II. Effects of extracellular potassium, furosemide, and membrane potential on $\mathrm{ECl}^{-}$in hippocampal CA3 neurons. J Neurophysiol 61:512-523. Medline

Timofeev I, Grenier F, Steriade M (2002) The role of chloride-dependent inhibition and the activity of fast-spiking neurons during cortical spikewave electrographic seizures. Neuroscience 114:1115-1132. CrossRef Medline

Trevelyan AJ, Sussillo D, Watson BO, Yuste R (2006) Modular propagation of epileptiform activity: evidence for an inhibitory veto in neocortex. J Neurosci 26:12447-12455. CrossRef Medline

Trevelyan AJ, Baldeweg T, van Drongelen W, Yuste R, Whittington M (2007a) The source of afterdischarge activity in neocortical tonic-clonic epilepsy. J Neurosci 27:13513-13519. CrossRef Medline

Trevelyan AJ, Sussillo D, Yuste R (2007b) Feedforward inhibition contributes to the control of epileptiform propagation speed. J Neurosci 27: 3383-3387. CrossRef Medline

Viitanen T, Ruusuvuori E, Kaila K, Voipio J (2010) The K+-Cl cotransporter KCC2 promotes GABAergic excitation in the mature rat hippocampus. J Physiol 588:1527-1540. CrossRef Medline

Wittner L, Maglóczky Z, Borhegyi Z, Halász P, Tóth S, Eross L, Szabó Z, Freund TF (2001) Preservation of perisomatic inhibitory input of granule cells in the epileptic human dentate gyrus. Neuroscience 108:587-600. CrossRef Medline

Wittner L, Eross L, Czirják S, Halász P, Freund TF, Maglóczky Z (2005) Surviving CAl pyramidal cells receive intact perisomatic inhibitory input in the human epileptic hippocampus. Brain 128:138-152. Medline

Yamamoto C, Kawai N (1967) Seizure discharges evoked in vitro in thin section from guinea pig hippocampus. Science 155:341-342. CrossRef Medline

Zhang F, Wang LP, Boyden ES, Deisseroth K (2006) Channelrhodopsin-2 and optical control of excitable cells. Nat Methods 3:785-792. CrossRef Medline

Zhang ZJ, Koifman J, Shin DS, Ye H, Florez CM, Zhang L, Valiante TA, Carlen PL (2012) Transition to seizure: ictal discharge is preceded by exhausted presynaptic GABA release in the hippocampal CA3 region. J Neurosci 32:2499-2512. CrossRef Medline

Ziburkus J, Cressman JR, Barreto E, Schiff SJ (2006) Interneuron and pyramidal cell interplay during in vitro seizure-like events. J Neurophysiol 95:3948-3954. CrossRef Medline

Zsiros V, Aradi I, Maccaferri G (2007) Propagation of postsynaptic currents and potentials via gap junctions in GABAergic networks of the rat hippocampus. J Physiol 578:527-544. CrossRef Medline 